\title{
Las implicaciones sociales y económicas de las unidades de intercambio solidario (UDIS) como medio de pago en CoopeVictoria
}

\author{
The social and economic implications of the solidarity exchange units (UDIS) as a means \\ of payment in CoopeVictoria \\ Mynor Molina Salas ${ }^{1}$
}

Fecha de recepción: 3-7-2019

Fecha de aprobación: 9-9-2019

\begin{abstract}
Resumen
El estudio presenta inicialmente un abordaje que contextualiza el tema de CoopeVictoria y el uso de las UDIS como medio de pago alternativo que utiliza esta cooperativa desde el año 2007, así mismo se analizan las bondades fundamentalmente sociales y económicas, así como las limitaciones del proyecto, a partir de las consideraciones de diferentes personas que fueron encuestadas, y de la aplicación de encuestas a tres diferentes poblaciones, los asociados y colaboradores de la cooperativa que han estado vinculados al proyecto, y los dueños o administradores de los negocios que participan como parte del núcleo de afiliados a este, y que por tanto también reciben UDIS como medio de pago por parte de sus clientes.
\end{abstract}

Palabras clave: unidades de intercambio solidario, monedas alternativas, implicaciones sociales y económicas, cooperativismo, economía social y solidaria, CoopeVictoria.

\begin{abstract}
The study initially presents an approach that contextualizes the theme of CoopeVictoria and the use of UDIS as an alternative means of payment used by this Cooperative since 2007 , as well as analyzing the fundamental social and economic benefits, as well as the limitations of the project, from the considerations of different people who were interviewed, and from the application of surveys to three different populations; the associates and collaborators of the cooperative that have been linked to the project, and the owners or managers of the businesses that participate as part of the core of affiliates to it, and therefore also receive UDIS as a means of payment by their customers.
\end{abstract}

Key words: solidarity exchange units, alternative currencies, social and economic implications, cooperativism, solidary economy, CoopeVictoria.

\footnotetext{
1 Magíster en Administración de Empresas. Departamento de Ciencias Sociales. Universidad de Costa Rica, Sede de Occidente. Costa Rica. Correo electrónico: molina@ucr.ac.cr / mainormolina@gmail.com
} 


\section{Introducción}

Con los procesos de globalización mundial que se han intensificado en los últimos años, buena parte de las compras que realizan los ciudadanos se transforman en compras mundiales y no locales, favoreciéndose no solo la cultura de consumo, sino que además los proveedores beneficiados son de otras latitudes, o al menos no forman parte de la economía comunitaria, y por tanto se desplazan los recursos fuera de sus propias comunidades.

Estas nuevas realidades que experimentan nuestras economías, fortalecidas por el robustecimiento de los modelos capitalistas, traen aparejadas por sí mismas fuertes y crecientes preocupaciones; principalmente, claro está, por parte de las clases menos privilegiadas, y ante estas realidades, a nivel mundial se buscan mecanismos que permitan al menos reducir los niveles de deterioro e impacto que se asocian a estos modelos económicos.

En el caso de Costa Rica, y aferradas al modelo cooperativo, surgen las denominadas monedas complementarias. Este medio de pago alternativo se configura en este caso a través de las "Unidades de Intercambio Solidario" (UDIS); buscando, tal como lo plantea Brenes (2010), el fortalecimiento de las economías locales, pues solo pueden ser utilizadas en los comercios que de previo hayan convenido recibir esta moneda, y los cuales a su vez están circunscritos a una región geográfica determinada. De esta forma se permite que la economía local se vea fortalecida.

A partir de lo anteriormente señalado, es oportuno indicar que el objetivo central de este artículo se concentra en el abordaje de los beneficios sociales y económicos que vienen aparejados a la implementación del proyecto UDIS por parte de CoopeVictoria -la cooperativa más emblemática del cantón de Grecia-, por otra parte y de forma concomitante, se pretende además realizar un abordaje más integral del tema, analizando los antecedentes que dan origen al surgimiento de esta moneda complementaria, así como su importancia, sus limitaciones, y como ha sido el desarrollo de este modelo a partir de su implementación en la cooperativa ya señalada.
Por otra parte, es importante mencionar que el artículo está estructurado del siguiente modo: en el apartado del marco teórico se desarrollan aquellos conceptos relevantes para la investigación, tal es el caso de la conceptualización del término "cooperativa", la historia de CoopeVictoria, los antecedentes de las monedas alternativas, el uso de UDIS como moneda alternativa y la conceptualización teórica de implicaciones sociales y económicas. En el apartado de la metodología se explican los instrumentos que se emplearon en la recolección de datos. En los resultados se anota la discusión acerca de los datos obtenidos. Finalmente, en las conclusiones se realiza una reflexión final en cuanto a los beneficios del uso de esta moneda.

Se pretende también que el proyecto de investigación pueda servir, además, no solo para robustecer el uso de este modelo en CoopeVictoria, sino que también pueda ser un insumo para que otras comunidades puedan replicarlo, con el objetivo común de fortalecer así las economías domésticas, la identidad comunitaria y convertirse en un motor de desarrollo para las comunidades donde a futuro puedan implementarse estos proyectos.

\section{Marco teórico}

\subsection{Conceptualización teórica de cooperativa}

El modelo cooperativo está fundamentado en la inexistencia de lucro por parte de sus asociados; además, las cooperativas se caracterizan también porque la adhesión y retiro es libre y voluntaria, donde la totalidad de los miembros comparten deberes y derechos y, contrario a otros modelos de negocios como las sociedades anónimas por ejemplo, cada asociado de forma independiente a la cantidad de capital aportado que posee u ostenta, tiene derecho a voz y un solo voto, lo que les permite convertirse en entes con un fuerte arraigo democrático, donde se fomenta y respira la igualdad de sus miembros.

De acuerdo con la Declaración de Identidad Cooperativa adoptada por la II Asamblea General de la ACI en 1995, se define a las cooperativas de la siguiente manera: 
Una cooperativa es una asociación autónoma de personas que se han unido voluntariamente para hacer frente a sus necesidades y aspiraciones económicas, sociales y culturales comunes por medio de una empresa de propiedad conjunta y democráticamente controlada.

El modelo cooperativo, pese a su longevidad, sigue estando vigente en la sociedad actual, y las razones para ello son muchas, destacándose fundamentalmente su esquema solidario, donde impera el interés mancomunado de las personas, que en común unión definen sus proyectos, sus metas y objetivos, al amparo de ilusiones, doctrinas y valores que siguen marcando el norte de este movimiento.

De esta manera, Cristiá menciona que las personas que forman parte de este modelo y su filosofía están preparadas y son coherentes con el progreso social y económico, buscando la mejora de las condiciones individuales y colectivas, así como la solidaridad, responsabilidad e igualdad en aras de generar un cambio de modelo económico en el quehacer diario y de las comunidades (2016, pp. 7-8).

De acuerdo con el último Censo Nacional Cooperativo, al 2012 Costa Rica contaba con 594 cooperativas activas y con 896.335 ciudadanos de todo el país que forman parte del movimiento cooperativo, lo cual significa que alrededor de un 21\% de los habitantes del país para esa época tenían un vínculo directo con el movimiento cooperativo (p. 17).

Lo anterior es importante, pues evidencia que el cooperativismo pese a que perdió el furor que tuvo a mediados del siglo anterior, donde surgieron cooperativas icónicas para Costa Rica como Cooperativa Dos Pinos y CoopeVictoria por ejemplo, sigue teniendo un gran arraigo en la cultura costarricense, y generando modelos y perspectivas de desarrollo social, que difieren de las empresas consideradas como mercantiles, donde su objetivo fundamental por no decir único se centra en la generación de utilidades para sus propietarios.
Por otra parte, no menos oportuno es indicar que las fortalezas de este modelo han permitido no solo la vigencia de este, sino que además tal como lo señala el autor Cristiá (2017) frente a la última crisis del capitalismo hegemónico, las cooperativas han tenido la capacidad de poder demostrar que, sin subsidios estatales, les fue posible lograr mayor estabilidad para soportar la debacle financiera (p. 7).

De esta forma las cooperativas siguen estando vigentes evidenciando que, supeditados a su doctrina y amplios valores humanistas que permean todo su desarrollo, es posible mejorar la calidad de vida de sus miembros y de sus familias, fomentando además el desarrollo de acciones que encajan de forma perfecta en los modelos de economía social solidaria, tales como el proyecto UDIS que ha desarrollado CoopeVictoria, y que por tanto no es de extrañar, como se detallará más adelante, que justamente la ONG denominada STRO (para más información visitar www.socialtrade.nl/?lang=es-Stro) y de origen holandés, haya decidido que sean las cooperativas el canal idóneo para el desarrollo de proyectos de tanto impacto como el de las UDIS.

\subsection{Historia de CoopeVictoria}

De acuerdo con el Balance Social Cooperativo de los años 2016-2017, CoopeVictoria R.L. es una cooperativa de tipo agroindustrial domiciliada en el cantón de Grecia, zona en la que desde el siglo anterior y hasta la fecha, y como parte de las actividades económicas más destacadas, está la producción e industrialización de caña y café.

CoopeVictoria, además de forma paralela a sus principales y más antiguas actividades, ha desarrollado otros negocios, que logran complementar de muy buena manera sus principales actividades económicas (industrialización de caña y café); es así como esta cooperativa cuenta con un almacén agrícola y ferretero, una estación de servicio que incluye una gasolinera, un lubricentro y locales de alquiler, un cementerio y una tostadora de café que le permite comercializar su producto tostado y molido, principalmente en la zona de Occidente. 
También, de acuerdo con el Balance Social Cooperativo 2016-2017:

Anterior a la cooperativa, desde 1905 existía la Hacienda Victoria propiedad de ciudadanos Alemanes, quienes construyeron una planta de industrialización para estos productos y a la cual los pequeños productores de la zona entregaban sus cosechas. Para la década del cuarenta a raíz de los conflictos armados a nivel mundial, en Costa Rica los bienes de los ciudadanos alemanes e italianos fueron confiscados por el gobierno de la República, esto incluyó a la Hacienda Victoria lo que provocó una situación de incertidumbre para los productores locales. Dada esta y otras situaciones se formó el Centro de Estudios para Problemas Nacionales, el cual recomendó la implementación de una cooperativa en Grecia. Posteriormente, a través de una promulgación del estado se vendió la Hacienda Victoria a productores locales para la creación de una Cooperativa Agroindustrial, lo que dio paso el 12 de octubre de 1943 a CoopeVictoria (p. 7).

Para mediados del siglo anterior, el modelo de desarrollo de Costa Rica estaba fuertemente arraigado a la agricultura y los monocultivos como el café. De esta forma, el modelo cooperativo desarrollado en torno al llamado "grano de oro" empieza a ganar terreno, pues permitió que los agricultores no solo obtuviesen mejores precios por sus cosechas, sino que además los acogió un movimiento noble y democrático, que para aquella época marcaba la pauta en el crecimiento y desarrollo de muchas poblaciones rurales, que veían en el modelo cooperativo la esperanza de lograr un modelo de desarrollo solidario, sostenible y guiado por principios y valores garantes de su funcionamiento, para de esta forma lograr excedentes para el sustento de las familias, cuyos miembros libremente optaban por formar parte de estos grupos.

De acuerdo con la versión del escritor e investigador Camilo Rodríguez, CoopeVictoria surge por el descontento existente entre los productores de caña de Grecia y de Poás, ante el abuso de un industrial de origen alemán que no pagaba precios justos, señalando además que esta empresa inició con veinte agricultores, principalmente de Grecia y algunos de la zona de Poás; luego el grupo de agricultores que ven nacer el proyecto de CoopeVictoria se acerca a los quinientos, sin embargo con dos o cinco manzanas de tierra no se sienten empresarios, pero si se convierten en asociados de una cooperativa industrial, esto les permite convertirse a su vez en empresarios.

De esta forma, y tal como sucede en la inmensa mayoría de los casos cuando se fundan cooperativas agrícolas, CoopeVictoria surge como una respuesta a la necesidad de los agricultores de agremiarse, normalmente en torno al tipo de cultivo que producen y la zona geográfica, con el fin de lograr de forma conjunta o colectiva más y mejores resultados de los que se podrían obtener si se comercializan sus productos de forma individual, de manera que se busca entonces que los beneficios se amplíen sobre una base democrática y solidaria de todos los miembros que componen la organización.

Como bien lo apuntan Zamora et al., la Cooperativa desde sus valores y visión cooperativa se ha dedicado a mejorar la condición socioeconómica de los productores agrícolas en su área de influencia a través de actividades como: pago oportuno y justo del valor de los productos, seguros de vida para sus productores y asociados, asesoramiento técnico gratuito, promoción permanente de la educación cooperativa, protección de áreas de conservación ambiental, producción de abono orgánico y, más recientemente, la implementación de proyectos de apreciación de los recursos locales a través de sistemas de intercambio local, tecnologías apropiadas orientadas a la proyección del medio ambiente, planes de gestión ambientales, entre otros (2017, p. 8).

Por lo tanto, CoopeVictoria R.L. es una institución sin fines de lucro, líder en la zona occidente de Costa Rica en la industrialización de café y caña de azúcar para pequeños productores, con crecientes unidades comerciales al servicio de los asociados y de la comunidad: "Es conocida por su impacto en el desarrollo socio económico de la zona, esa posición ha generado un reconocimiento local y una responsabilidad social con la población, lo cual nos compromete a realizar nuestras acciones acorde con los principios y valores de nuestra cooperativa” (2010,p. 8). 


\subsection{Antecedentes de las monedas alternativas}

Con los procesos de globalización en el comercio mundial, que se han intensificado en los últimos años, las personas se han convertido en ciudadanos del mundo, abandonando poco a poco sus raíces y adoptando modas e ideas que les son ajenas; perdiendo de esta forma sus propias identidades y transformándose, principalmente los nativos digitales, en compradores compulsivos de marcas y productos que están tan solo a un "click" de distancia gracias a Internet. De esta forma sus compras se transforman en compras mundiales y no locales, favoreciéndose no solo la cultura de consumo, sino que además los proveedores beneficiados son de otras latitudes, o al menos fuera de la economía comunitaria, y por tanto se desplazan los recursos fuera de la comunidad y en el peor de los casos fuera de las fronteras nacionales.

Ante todas estas realidades, la humanidad ha venido buscando alternativas que puedan generar un contrapeso a los modelos económicos tradicionales, y a estos procesos globalizantes; de esta forma el desarrollo del cooperativismo, los bancos de tiempo o las monedas alternativas, por ejemplo, constituyen acciones que buscan mitigar los resultados de estos modelos inhibitorios del bien común.

De acuerdo con Constanza, Farley y otros (2003), citados por Shephard (2011), en el caso particular de las monedas alternativas, si bien existen desde hace siglos, se aprecia un resurgimiento de su uso bajo nuevos patrones en distintas regiones del mundo, especialmente en las tres últimas décadas del siglo XX, y en el curso de la actual década del siglo XXI. Las mismas exhiben orígenes, caracteres y dimensiones diferentes en las ciudades de varios países, con una diversificación y aumento de cantidad, alcanzándose los 5000 tipos (p. 31).

En este mismo sentido, Brenes (2013) afirma que "numerosas comunidades alrededor de todo el mundo están emitiendo sus propios medios de pago para volver a reorganizar sus economías locales" (p. 122), señalando además este mismo autor que a este fenómeno se le llama localismo monetario o redes monetarias locales.
Este acrecentamiento en el uso de monedas alternativas en las últimas décadas está en clara consonancia con las crisis y las difíciles realidades económicas y sociales que ostentan muchos países alrededor del mundo, y no es de extrañar entonces que estos modelos alternativos hayan venido consolidándose con el transcurso del tiempo, y permitiendo usualmente de forma paralela un aumento en el poder adquisitivo de las personas participantes, un fortalecimiento de la economía local, y una mayor preocupación por el resguardo del medio ambiente, tal como se describirá más adelante con el modelo que ha desarrollado CoopeVictoria.

Por otra parte, Cortés afirma que "los sistemas monetarios sociales se enmarcan en la economía de la solidaridad” (p. 8), y de forma adicional en el mismo sentido Chaparro (2014) amplía al señalar que el marco desde el cual se abordan los sistemas monetarios complementarios se orientan en un enfoque humanista de la economía, que encuentran en la economía social y solidaria un referente importante, pues esta abraza una perspectiva no solo económica, sino también ambiental, ética y filosófica (p. 7).

Queda claro entonces que las monedas alternativas se circunscriben a un modelo económico que evidentemente resulta también alternativo; es decir, el modelo económico dominante por un lado y el "dinero genuino" como su aliado, que es parte entonces de este modelo y que poco a poco han venido ganando espacio en diversos estados o naciones, que eso sí, no desisten en su afán de defender su lógica egocéntrica, en el sentido de que corresponde únicamente a estos entes el monopolio absoluto en la emisión y control de sus monedas oficiales y que deben entenderse estas como el único medio de intercambio oficial y válido.

En este mismo sentido, Hirota señala que una de las diferencias fundamentales consiste en que la creación del dinero convencional corresponde a la banca, para que este sector maximice sus beneficios en detrimento del resto de cada economía, cosa que no sucede con las monedas complementarias, pues en estos casos el dinero se crea por medio de procesos controlados por el sector no lucrativo 
para facilitar transacciones; generándose que la creación del dinero convencional solo se ejerce cuando se prevén lucros financieros, mientras que la de monedas complementarias cuando se cumplan condiciones necesarias (2011, p. 24).

\subsection{Conceptualización de monedas alternativas}

La inexorable búsqueda de los seres humanos de generar procesos de intercambio, con el fin de satisfacer sus necesidades, los ha llevado con el transcurrir de los años a diseñar diferentes modelos que les permita librarse del rústico esquema de autosubsistencia. En este sentido y desde épocas inmemoriales, la humanidad inicia el desarrollo de actividades comerciales, los modelos de trueque para el intercambio de sus productos, $y$ posteriormente se desarrolla el concepto de moneda, que de forma evidente ha facilitado enormemente la satisfacción de esas necesidades. En este sentido, y de acuerdo con la versión de Bustamante et al., existen de forma general dos tipos de monedas:

La moneda convencional es emitida por los bancos centrales de cada país, es la moneda oficial que se usa para intercambiar bienes y servicios, usada como un símbolo de valor. [...] El dinero depende de un Estado nacional geográficamente delimitado; una moneda nacional, es identificada por los ciudadanos y equivale a un sistema de información compartida. El dinero es fiduciario, es decir, es creado de la nada (fiat money). En la actualidad, por cada depósito que reciben los bancos, el Banco Central (La FED) imprime dinero o lo genera en forma de préstamos a clientes. El dinero es escaso debido a que para que funcione un sistema de moneda basado en la deuda bancaria, debe introducirse la escasez y preservarla en forma artificial y sistemática. Todas las monedas nacionales actuales generan interés, es decir, el pago de intereses no es algo intrínseco al dinero, es una decisión que toman los bancos. La moneda alternativa por su lado es emitida por grupos sociales e instituciones que promueven iniciativas de desarrollo social. Cumple al igual que el dinero convencional algunas de las funciones más importantes, como medio de intercambio y estándar de valor, pero por su propia naturaleza no es capaz de acumular riqueza (2012, p. 55).

Es importante destacar entonces que existe una similitud indiscutible entre estas monedas, sobre todo porque ambas cumplen con el objetivo fundamental de servir de medio de intercambio, lo que les permite a ambas eliminar la complejidad del trueque para el desarrollo de los intercambios. Pero, por otro lado, se distinguen diferencias importantes como el hecho de que las monedas oficiales son de circulación general en los países, o inclusive de forma más globalizada como sucede con el dólar, por ejemplo, y no se circunscriben a comunidades en específico como ocurre con las monedas alternativas.

Otra diferencia que señala el autor recién citado, y de la que vale la pena hacer mención, es el hecho de que estas monedas no están asociadas al concepto de acumulación de riqueza, esto por cuanto la bondad del sistema radica en su circulación permanente y, como ya se dijo, en zonas o ciudades exclusivas, por lo que unido al hecho de que de forma típica no devengan intereses por su acumulación, queda claro entonces que la no acumulación de riqueza es por tanto una diferencia sustancial de las monedas alternativas respecto de las monedas oficiales.

Por otra parte, es oportuno señalar que estas monedas no convencionales, según Liater (2005), Lopezllera (2002) y Primavera (2001), citado por Corrons (2017), reciben diferentes nombres, los cuales se detallan enseguida:

Complementarias: porque complementan con el dinero convencional, al que en ningún momento pretenden reemplazar.

Alternativas: porque funcionan en lugar del dinero convencional en ciertos contextos.

Comunitarias: porque funcionan en comunidades de personas o entidades que se relacionan directamente y desean establecer un medio de intercambio distinto. 
Locales/Regionales: porque circulan en lugares y espacios delimitados.

Sociales: porque son creadas, emitidas y controladas por grupos sociales. (p. 110).

Este mismo autor aclara que "las monedas complementarias constituyen un símbolo de valor que un grupo de personas acuerdan emitir y utilizar para realizar intercambios de bienes y servicios" (2017, p. 109); a partir de esta definición queda claro que tal como ya había sido mencionado en el apartado anterior, estas monedas, similar a las convencionales, poseen un valor que les permite su circulación en algunas comunidades particulares, para ser utilizadas tal cual sucede con una moneda convencional para transar bienes y servicios.

La creación y crecimiento de estos modelos alternativos dan cuenta de que es posible para las comunidades organizarse en torno a patrones económicos no tradicionales; lo que permite, además, desmitificar el hecho de que solamente las monedas oficiales son los únicos medios válidos para generar procesos de intercambio.

\subsection{Conceptualización de UDIS}

De acuerdo con el artículo denominado "Dinero Social: UDIS en Centroamérica", a partir del año 2006, el entorno financiero y bancario de la región presenta una importante transformación, asociada básicamente a la consolidación bancaria, el impulso a la modernización del sistema financiero, y la crisis financiera global, y es justo en ese momento cuando en la región empiezan a surgir las monedas locales o comunitarias, destacándose en la región las llamadas Unidades de Intercambio Solidario (UDIS), usadas desde el año 2003 en Honduras y replicadas posteriormente en Costa Rica y el Salvador, en todos los casos impulsadas por la fundación Stro (García, 2013, pp. 1-2).

Es importante mencionar que la fundación STRO es un ente internacional autónomo y sin fines de lucro con sede en Holanda. Es la precursora de este modelo solidario y a su vez ha brindado apoyo a las anteriores cooperativas en sus proyectos de monedas alternativas; según la página www.stro-ca.org, bajo este sistema la gente intercambia productos y servicios con una unidad de intercambio interna en vez de con dinero.

Así como en otras latitudes se han desarrollado multitud de proyectos con monedas alternativas, en el caso de los países antes señalados se desarrollan particularmente estas, denominadas Unidades de Intercambio Solidario, que como su mismo nombre lo indica, permiten que las personas que forman parte de las redes en cada región puedan utilizar estas monedas para intercambiar bienes y servicios entre ellas, sin necesidad de recurrir al trueque pero tampoco al uso de las monedas de uso corriente en cada país.

UDIS es el acrónimo de Unidades de Intercambio Solidario y, según García, son un medio de cambio solamente aceptado dentro de la comunidad o entidad que acepta su uso; fuera de ese círculo no posee ningún poder liberatorio (2011, p. 3).

Pese a que las UDIS toman la apariencia de un típico billete emitido por cualquier entidad bancaria, con sus normas de seguridad inclusive, muchos autores aclaran que se trata de vales, o vales comunitarios. En este mismo sentido, y de acuerdo con la versión de Henry Vargas, Gerente Financiero de CoopeVictoria, es un vale que funciona como unidad de intercambio.

Por otra parte, Bustamante et al.,señalan que, desde la concepción marxista, esta moneda alternativa no cumple con todas las funciones del dinero, lo anterior debido a que el UDIS no es reserva de valor, ya que no se puede ahorrar ni genera valor en el tiempo tras su atesoramiento, $y$ tampoco es un patrón de precios, ya que las personas no colocan el precio de los productos pensando en UDIS, sino más bien en el Dinero Oficial (2012, p. 80).

Por otra parte, es oportuno rescatar el hecho de que el autor antes citado, hace hincapié en el sentido de que las UDIS justamente no funcionan como reserva de valor, principalmente por el hecho de que aun cuando se decida ahorrarlos, no es posible esperar para los beneficiarios ningún crecimiento o aumento en su capital de UDIS, al 
no generar intereses como de ordinario sucede con las monedas oficiales.

Es importante señalar también que las UDIS han encontrado tierra fértil en las cooperativas, y en realidad esto no es de extrañar, pues estas empresas como es conocido tienen un fuerte arraigo hacia los principios de solidaridad y ayuda mutua, promoviendo el bien común de todos sus agremiados, y en este tanto, es entonces que los proyectos de UDIS comulgan con los principios cooperativos (ayuda mutua, solidaridad, responsabilidad, igualdad, equidad y democracia), y por tanto estos se complementan perfectamente para lograr una especie de sinergia en favor de las economías domésticas.

De acuerdo con Jiménez y de Beer (2007), citados por Bustamante et al., (2012):

A nivel macro la implementación de modelo de vales fortalecería las relaciones económicas locales en la zona o región donde circulan los vales, siendo el vale únicamente aceptado como medio de pago local, lo que evita que el poder adquisitivo escape fuera de la economía local. El fortalecimiento de las relaciones comerciales locales, fomentaría también las relaciones sociales dentro de la comunidad o región (p. 82).

En relación con el desplazamiento del poder adquisitivo fuera de las economías locales, es claro que los grandes centros comerciales que proliferaron hace algunas décadas, más el auge del comercio electrónico en los últimos años y con mayor impacto, sin duda han favorecido el traslado de capitales; por tanto las UDIS representan una clara alternativa para detener en alguna medida el desplazamiento de esos capitales y fomentar el espíritu solidario entre las personas y comercios que participan en estos proyectos, donde la moneda recircula entre estos grupos específicos de personas, que buscan gastar las UDIS en los comercios afiliados, y estos a su vez procurarán la misma acción, permitiendo entonces esta recirculación entre los participantes, hasta que estas lleguen nuevamente hasta el ente emisor.

\subsection{El inicio del proyecto UDIS en CoopeVictoria y su funcionamiento}

Quien fungiera como asesor técnico de Stro en la década anterior (Brenes Mata) expresó como antecedente del proyecto UDIS en CoopeVictoria que, los primeros acercamientos se suscitaron en año el 2007, pues esta empresa (Stro) recibe recursos para apoyar la región centroamericana. Así inicialmente se elige a Honduras dada su situación social, luego el Salvador y Costa Rica, también se intentó en Nicaragua, pero no fue posible concretar en ese entonces ninguna iniciativa en este país.

Es importante señalar además que el apadrinamiento de Stro en el proyecto duró hasta el año 2010. Además, según lo que se refiere en el texto inédito "informe inicial":

Respecto al financiamiento inicial del proyecto, Stro fue el responsable de donar a la Cooperativa el costo de los vales, además de €10.000 (10.000 euros) equivalentes a $\$ 6.7$ millones, con el fin de promocionar el esquema de vales, y cubrir también el costo de capacitación de los funcionarios (Pérez, p. 8).

Además, Brenes Mata expone que la identificación de las contrapartes en Costa Rica para desarrollar el proyecto de UDIS fue un tanto aleatorio, pero el requerimiento inicial e indispensable propuesto definido por esta ONG, es que los entes candidatos a participar con el desarrollo de esta iniciativa fueran parte de la economía social y solidaria, pues caso contrario no se generaría ningún tipo de financiamiento para su desarrollo. Tomada esta decisión, se empezaron a buscar cooperativas con cierto perfil productivo que estuviesen asociadas a la actividad agrícola, y que su nivel de impacto en sus comunidades fuese bastante visible e importante; así se buscan algunas alternativas, varias de ellas como el caso de Cooprena y Coopeagri, donde los proyectos no logran concretarse, condición contraria a CoopeVictoria en la ciudad de Grecia, CoopeBrisas en Zarcero y CoopeSilencio en la ciudad de Quepos, donde sí se logra concretar esta iniciativa. 
Es importante señalar que la versión del señor Brenes Mata coincide perfectamente con la literatura revisada; esto en el sentido de que las UDIS nacen en el contexto de asociaciones o cooperativas que forman parte de la economía social y solidaria, lo que les permite a los asociados ser partícipes de primera mano en el desarrollo e impulso de estos proyectos.

De esta forma, y según lo detalla Juan Pérez en su informe que se encuentra inédito, luego de analizar varios modelos de incentivos se toma la decisión de retribuir al asociado un $2 \%$ en UDIS sobre sus compras mensuales de crédito o contado hechas en la Estación de Servicio, el Almacén de Suministros y los productos que están a la venta en la recepción de CoopeVictoria, los cuales inicialmente solo podrían hacerse efectivos mediante el canje por mercancías o servicios en esas mismas áreas comerciales. Además, la participación en el esquema de vales se aplica exclusivamente a los asociados de la Cooperativa Agrícola Industrial Victoria y sus sociedades, asignándose un vale de 1.000 UDIS por cada \$50.000 acumulados de compras durante el mes.

De lo anteriormente expuesto se evidencia que el proyecto UDIS en CoopeVictoria inicia dando participación exclusiva a los asociados de esta cooperativa y además surge como un modelo de tantos otros que existen en el mercado denominados "programas de fidelización", los cuales en un sentido amplio a través de programas de puntos, millas, vales o descuentos especiales, por ejemplo, buscan atraer nuevos clientes y promover mayor fidelidad por parte de estos, logrando que los clientes se sientan motivados por estas recompensas, y de esta forma reiteren sus compras en los locales que ofrecen estos incentivos.

A la luz de lo anterior, podría interpretarse que este esquema inicial de promoción del proyecto UDIS, al buscar básicamente fidelización, resulta ajena a una acción solidaria, pues encaja más bien en una práctica mercadológica tradicional, sin embargo no puede obviarse el hecho de que las cooperativas por su misma naturaleza y concepción forman parte de la economía social solidaria; es decir; la acción que se busca es fidelizar, pero se desarrolla en una entidad cooperativa cuyos valores tales como ayuda mutua, igualdad y solidaridad, por ejemplo, son claramente representativos de este movimiento.

En el documento antes citado se aclara también que en cuanto a la equivalencia 1 UDIS es igual a 1 colón, las denominaciones existentes son de 1000, 2000, 5000 y 10.00o UDIS; además se define que al finalizar cada mes los asociados podrán retirar los vales correspondientes en las cajas de la estación de servicio, el almacén de suministros o la caja central de la cooperativa y, en el caso de las compras a crédito, los vales solo podrán retirarse hasta el momento de cancelación de la factura, y esto debe ser antes de los 60 días de que esta haya sido emitida.

Según lo recién mencionado, las denominaciones de UDIS emitidas, salvo por el billete de 20.00o, coincide de forma exacta con los billetes de mayor circulación de la moneda nacional en Costa Rica, es decir los colones; además puede apreciarse también que al inicio del proyecto se definió que la participación en él fuese exclusivamente para los asociados de la cooperativa.

Por otra parte, y de acuerdo con lo señalado por Brenes Mata, en el caso de CoopeVictoria el lanzamiento de las UDIS, como ya se ha dicho, se generó bajo el marco metodológico de Stro, particularmente bajo la fisonomía de las monedas locales del tipo CBC (por sus siglas en inglés significa moneda respaldada como un comodity), que en este caso particular dado el giro de esta cooperativa son el café y la caña, producción que de esta forma respalda el giro de esta moneda por parte de CoopeVictoria.

Respecto a este esquema de incentivos con el cual justamente dio inicio el proyecto de UDIS, es oportuno señalar que, según Zamora (2010p. 15), este programa luego de 11 años de funcionamiento fue suspendido temporalmente durante el año 2018, dicha suspensión se generó debido fundamentalmente a razones financieras, los bajos precios del café, y los problemas de precio que se generan por la extra cuota del azúcar. 
Paralelamente al desarrollo del modelo de incentivos para los productores vía UDIS, según Zamora, existía ya desde el mismo 2007 la iniciativa de ir complementando el proyecto con otras actividades de interés comunitario, es así como en el año 2008 ve la luz la segunda etapa de la iniciativa UDIS, según la cual la cooperativa desarrolla un modelo de producción de biodiesel a partir del aceite de cocina quemado, el cual es cancelado con UDIS y proveído principalmente por los niños de las diferentes escuelas del cantón de Grecia y por algunos comercios, fundamentalmente hoteles y restaurantes.

El planeta indefectiblemente necesita un respiro, variables como la industrialización, que fuertemente arranca su despliegue en el siglo anterior, la obsolescencia programada, el fuerte incremento en la flotilla vehicular, la tala indiscriminada de árboles, la contaminación de mares, ríos y suelos no dan tregua, sin un compromiso real de las personas y las empresas por buscar acciones conjuntas, para al menos detener el caos que literal e inexorablemente nos mata de forma cotidiana, será imposible heredar a las nuevas generaciones nuevos modelos de desarrollo, mucho menos salvajes y más comprometidos con el desarrollo de prácticas sostenibles y sustentables.

Este es un programa de ayuda al ambiente y ayuda social, además de promover en las personas y niños la no contaminación y el cuidado con el medio ambiente. Algo que nos motiva también a seguir con el proyecto es que pensamos que el combustible convencional de petróleo es escaso a nivel mundial, que no hay en el país y con este proyecto estamos produciendo a nivel local un combustible que está generando empleo y ayudando al ambiente (Zamora, 2010, p. 10).

Tal como lo expone Bogantes de la revista mensual Entre Cantones, este biocombustible:

Es biodegradable, amigable con el ambiente, 80\% menos contaminante, no es cancerígeno y limpia el sistema de combustible. Estas son solo algunas de las muchas razones por las que Cooperativa
Victoria R.L. en Grecia ha puesto a disposición de todos los usuarios o dueños de vehículos el Biodiesel (2010, p. 10).

En sintonía con la clara noción de que no puede mantenerse al margen de los problemas ambientales, y conocedora además de que el modelo cooperativo por naturaleza forma parte de la economía social solidaria ,es que justamente CoopeVictoria se decide a emprender esta acción adicional, donde queda evidencia manifiesta de su fuerte compromiso y proyección social con la comunidad, que le permite entonces liderar procesos de innovación a nivel nacional.

Según Esquivel en la emisora radial Radio 16, la producción del Biodiesel se realiza en la planta que la cooperativa destinó para estos efectos en el Mesón de Grecia, el proyecto inició con 55 escuelas en las que los estudiantes llevan el aceite quemado de sus hogares, el cual para los inicios del proyecto se cancelaba el litro a \$140.00, y el dinero lo utilizan en las escuelas para la compra de implementos en beneficio de la educación de los infantes.

Resulta imponderable el dejar de mencionar y exaltar el hecho de que esta iniciativa realmente presenta beneficios que, desde cualquier óptica, conllevan un espíritu eminentemente solidario con el medio ambiente, con la comunidad de Grecia y con el planeta como un todo, evidenciándose entre otras las siguientes ventajas que menciona González:

Como fuente de contaminación, un litro de aceite usado contiene aproximadamente 5.000 veces más carga contaminante que el agua residual que circula por las alcantarillas y redes de saneamiento y puede llegar a contaminar 40.000 litros de agua, que es equivalente al consumo de agua anual de una persona en su domicilio.

Si ya de por sí el mero hecho de convertir aceite de cocina quemado en biodiesel tiene un impacto increíblemente positivo para el medio ambiente, al evitar que estos desechos se viertan por los fregaderos y se conviertan en un contaminante de primer orden, ahora resulta fundamental considerar también que el combustible 
generado no es de origen fósil y por tanto se considera que "reduce la contaminación ambiental en un 100 por ciento, debido a que es biodegradable" (Universia, 2010).

Otro beneficio importante es el hecho de que mejora los ingresos de las escuelas, genera empleos adicionales para el transporte y fabricación del producto, y además fomenta la disciplina en los niños de edad escolar, elementos que se analizarán también en la sección de beneficios sociales y económicos.

Pese a los cuantiosos e encomiables beneficios de este proyecto, no puede dejarse de lado que este en los últimos años ha venido decreciendo, según lo que menciona Zamora, de tal forma que a la fecha solo 13 de las 55 escuelas se mantienen activas con el proceso de recolección de aceite quemado, y ha disminuido también el número de otros suplidores de este producto; las razones fundamentales que han originado el decrecimiento del proyecto básicamente se explican por el hecho de que la cooperativa por asuntos económicos ha reducido sus niveles de inversión para esta iniciativa, además de que existe ahora competencia por la compra de la materia prima, donde la porcicultura compite directamente por la compra del aceite quemado, además de que dados los costos de producción, a la fecha el precio que se paga por el litro de materia es de apenas $\$ 100,00$, cuando en los albores del proyecto se llegó a pagar hasta $\$ 140,00$ el litro.

Para continuar de forma secuencial con el desarrollo del proyecto UDIS, en el año 2009 se toma la decisión de iniciar lo que podría llamarse la tercera etapa del proyecto, que consistía en lograr que los vales fuesen recibidos en una red de comercios locales, ubicados en los cantones de Grecia y Poás; así mismo, generar la opción de brindar a los colaboradores la posibilidad de que de manera voluntaria pudiesen recibir una parte de sus salarios en esta moneda alternativa.

De esta forma se inicia el desarrollo de una etapa más del proyecto, considerada como primordial, dado que es justamente con esta fase donde se inicia un plan de comunicación masiva que básicamente pretende dar a conocer a los usuarios de UDIS las nuevas opciones a nivel de comercio local para poder usar sus vales.
En este sentido se logra evidenciar que el proyecto arranca con un total de 19 negocios que han acordado con CoopeVictoria recibir los vales, destacándose así la existencia de supermercados, farmacias, tiendas, librerías, y al menos una carnicería, una panadería y un laboratorio clínico, entre otros; a la fecha se mantienen activos 18 comercios, pero buena parte de los administradores o dueños de ellos como se detallará más adelante, coinciden en que el proyecto ha venido a menos, y consideran que apenas es regular o malo.

Resulta evidente entonces que con esta tercera etapa en el desarrollo de la iniciativa UDIS se intensifica el uso de los vales, dado que ya las personas que forman parte del proyecto no solo pueden usarlos en los negocios de la cooperativa, sino que también en otros negocios principalmente del cantón de Grecia y algunos de Poás, cantón vecino donde existe una influencia importante de CoopeVictoria.

Por otra parte, no es oportuno dejar de lado que en esta etapa no solo se abre el abanico de posibilidades con la apertura del proyecto hacia otros comercios de la comunidad, sino que además se permite a los colaboradores para que libremente puedan participar en el plan, admitiendo que parte de sus salarios se les cancele en UDIS, originando así que no solo se promueva el ahorro, sino que también se beneficien de las políticas de descuentos ofrecidos por los distintos comercios que participan en el proyecto.

En el caso de los empleados de la Cooperativa, se logra evidenciar que este modelo coherente con las prácticas de la economía social solidaria permite fundamentalmente dos cosas:

1. Que se les pague una parte de su salario en UDIS, con lo cual ellos tienen la posibilidad de que con estos vales también puedan aprovechar los descuentos que se ofrecen en los comercios afiliados, teniendo la condición adicional de que al no ser moneda de curso ordinario, por una parte se fortalece la cultura del ahorro, pues no es posible gastar las UDIS en cualquier lugar, y por otra parte cuando se decide utilizarlos, pues como ya se ha mencionado solo puede hacerse en la red de comercios 
afiliados, generándose así un microciclo de traslado monetario, donde está ausente la moneda nacional, y CoopeVictoria se convierte entonces en el ente emisor y receptor de la moneda alternativa.

2. Motivarlos para que se asocien a la cooperativa, contrario a lo que sucede en el ordinario de los negocios, donde escasamente se da la posibilidad a los funcionarios de ser y sentirse propietarios de estos, en este caso más bien, no solo se les da la posibilidad de ser parte de la base asociativa y por tanto codueños del negocio, sino que además se les incentiva regalándoles UDIS, que como ya se ha señalado anteriormente provienen de los premios que se obtienen al gozar de la certificación de Comercio Justo:

Es un sello de garantía que funciona como distintivo positivo ofreciendo al consumidor seguridad acerca de los valores éticos del producto. Los productos que llevan el sello Fairtrade han sido producidos en condiciones de trabajo dignas y comprados a un precio justo que apoya el desarrollo sostenible de la organización productora (Fairtrade).

De esta forma, esta "moneda alternativa" permite que la economía local se vea fortalecida, pues esta divisa al tener un emisor local y no poder usarse en otros lugares y menos aún para compras por Internet mediante el comercio electrónico, genera por defecto que sean únicamente los negocios de la región quienes se vean beneficiados con las compras de sus clientes, quienes además pueden también recibir como incentivo adicional la aplicación de descuentos, que no recibirían si pagan con la moneda oficial o cualquier otro medio de pago, logrando de esta forma beneficios mutuos y el fortalecimiento de las economías locales.

Nótese que con estas decisiones se potencializa indudablemente el valor solidario que caracteriza al movimiento cooperativo en general, y a CoopeVictoria en particular, pues se logra mediante las UDIS articular un entramado de acciones de mutuo beneficio, donde el modelo propuesto rescata la participación de niños, maestros, asociados, colaboradores y comerciantes, que unidos junto a CoopeVictoria dan forma a un modelo económico inédito hasta la fecha en Costa Rica.
Por otra parte, es oportuno señalar que como complemento de las acciones sociales desarrolladas por CoopeVictoria, esta cooperativa cuenta entre otras con la certificación conocida como Comercio Justo, la cual le permite un reconocimiento económico para los negocios que la ostentan por sus buenas prácticas, pero además permite que los negocios sean retribuidos con bonos o sobreprecios al vender sus cosechas.

De esta forma, según lo que menciona Zamora, la cooperativa toma la decisión de que estos sobreprecios ganados u obtenidos mediante la certificación antes mencionada se reparta entre los asociados, los colaboradores y la comunidad, mediante regalías o donaciones, dicha decisión es tomada de forma anual por el máximo órgano decisorio, denominado la Asamblea General de Asociados.

La práctica al menos en los últimos años es que los asociados reciban la parte que les corresponde en especie, normalmente en almácigos o insumos agrícolas, mientras que la comunidad se beneficia también por medio de las donaciones en UDIS que se brinda a instituciones como la Cruz Roja o Cuidados Paliativos por ejemplo, y por otra parte a los colaboradores se les cancela también dichos beneficios en UDIS; en este último caso esta retribución extraordinaria se da de forma exclusiva a aquellos funcionarios que tienen la doble condición de colaboradores y asociados, esto con la intención de motivar a que más colaboradores se asocien a la Cooperativa.

Como se rescata de lo anteriormente mencionado, con esta iniciativa se logra además que las UDIS pasen a formar parte del programa de donaciones de CoopeVictoria, rescatando el hecho de que como es usual en el sistema cooperativo, existan programas de donaciones para instituciones de bien social, pero en este caso la singularidad se evidencia en el hecho de que estas son ahora en este tipo de vales, con lo cual se inhibe a los beneficiarios para que puedan usar estos recursos fuera de la economía local, favoreciéndose de nuevo más bien la economía comunitaria, al incentivar las compras en los diversos comercios que forman parte del sistema. 
Otro de los mecanismos ideados por CoopeVictoria para incrementar la circulación de su moneda alternativa, según Zamora (2010, p. 18), se generó a partir de la decisión del Consejo de Administración de cancelar las dietas de los directores y de los miembros de los comités en un 50\% con UDIS. Como queda claro, solo los afiliados al programa pueden usar las UDIS, y es la Cooperativa Victoria quien define cuales son los comercios, instituciones y personas que pueden formar parte de este proyecto.

Según lo señalado por Henry Vargas, la cooperativa tiene la responsabilidad expresa de controlar la emisión y circulación de UDIS, además de que a la fecha el proyecto se encuentra en una etapa de impase a partir del análisis de los objetivos iniciales propuestos del proyecto. También es importante señalar que, pese a las cuantiosas bondades del proyecto, ha venido en decrecimiento.

A la fecha es importante señalar que de las tres cooperativas donde se logra desarrollar inicialmente el proyecto, CoopeBrisas decidió hace algunos años no continuar más con él, quedando entonces solamente en el país dos cooperativas que usan UDIS, CoopeVictoria domiciliada en Grecia de Alajuela y CoopeSilencio en el cantón de Quepos de Puntarenas.

Aun cuando a nivel de CoopeVictoria, como se verá más adelante, se han utilizado las UDIS como "un sistema de vales”, finalmente su uso en la práctica es similar (con algunas excepciones) al que se les da a otras monedas que circulan en el país como el colón y el dólar principalmente.

\subsection{Conceptualización teórica de implicaciones sociales y económicas}

El presente trabajo de investigación posee dos vertientes importantes de desarrollar antes de comenzar con el análisis de los datos recopilados. En cuanto al factor económico, López y Gentile mencionan que la importancia de los indicadores económicos radica "no solo en que son elementales para evaluar, dar seguimiento y predecir tendencias de la situación de la región, sino que también son necesarios para valorar el desempeño de cada uno de los programas encaminados a lograr el cumplimiento de las metas y objetivos fijados” (p. 12).
La parte social del proyecto consiste en los beneficios que reciben los involucrados en el proceso, pero desde una perspectiva más integral, es decir, donde se tome en cuenta desde la seguridad hasta el ambiente que rodea a los participantes del estudio: Cualquier ciencia, incluida la social, solo puede nacer y desarrollarse cuando tiene terreno para ello, cuando hay condiciones sociales concretas y cuando lo impone la necesidad social (Lahera, 2013). De esta manera, estas mismas autoras indican que:

Si bien las estadísticas sociales se están convirtiendo en un grupo con mayor importancia cada vez dentro de la estadística oficial, ya que en la actualidad la mayor parte de esta de alguna manera es social o bien tiene una indisoluble relación con lo social, en el pasado el término "social" se utilizaba para las estadísticas referidas a los aspectos menos económicos, al punto que parecía una categoría casi "residual”. Las nuevas situaciones sociales -cambio familiar, dificultades de los jóvenes para acceder a un empleo estable, mayor peso demográfico de las personas mayores, acceso de la mujer al mercado de trabajo- son retos a los que no se puede responder únicamente con información económica. Queda ya superada aquella época en la que se identificaba causalmente el crecimiento económico con el bienestar social. (Lahera, 2013, p. 6)

De esta manera, esta investigación pretende recopilar y analizar las implicaciones tanto económicas como sociales que el proyecto de UDIS que se desarrolla en CoopeVictoria.

\section{Metodología}

Para el desarrollo de este estudio se procedió con la aplicación de herramientas de investigación cualitativa y cuantitativa. Se utilizó como instrumento de recolección de datos la encuesta, de manera que en relación con las primeras, se generó un proceso de recolección, revisión y análisis de información bibliográfica y, posteriormente, se procedió con la recolección de información principalmente a 28 funcionarios de la cooperativa, que tienen o han tenido relación estricta con el desarrollo del proyecto, además se entrevistó también a un exfuncionario de la 
empresa Stro que estuvo asesorando a CoopeVictoria en el desarrollo e inicios del proyecto de UDIS. Es importante mencionar que se entrevistó a 15 dueños de comercios y 50 asociados.

Las encuestas se realizaron en el lugar donde laboran cada uno de los funcionarios de la cooperativa y, en el caso del ex - asesor de Stro, se generó en la propia oficina de trabajo, de quien funge como asesor externo principalmente en temas de economía social solidaria. En todos los casos las encuestas se realizaron mediante visitas acordadas de forma previa.

Respecto a la parte cuantitativa, y dado que es fundamental conocer de primera mano la opinión de los principales actores en el manejo de las UDIS, se tomó la decisión de dividir la población total en tres diferentes poblaciones, dado que las características de cada una de ellas son diferentes, y desarrollar y aplicar de esta forma una encuesta diferente para cada población, procurando evaluar en cada caso los beneficios económicos y sociales que ha traído el proyecto, así como la debilidades y la percepción de las personas sobre la posibilidad de que dicha idea sea desarrollada en otras cooperativas:

\section{Colaboradores}

En el caso de los colaboradores, se optó por trabajar con la totalidad o el universo de ellos que según los registros de CoopeVictoria han tomado la libre decisión de que una parte de su salario semanal se les cancele con UDIS. Los cuestionarios fueron aplicados de forma personal durante los meses de julio y agosto de 2018. La encuesta se aplicó directamente en el lugar de trabajo de cada colaborador.

El total de los colaboradores que participan en el proyecto son 29, de los cuales fue posible aplicar el instrumento a 28 de ellos, que corresponde a un $97 \%$ de esta población.

\section{Comerciantes}

De manera similar, respecto a los comerciantes, se decidió trabajar con el listado total que según la información de la cooperativa reciben UDIS como parte del giro normal del negocio. Los cuestionarios fueron aplicados personalmente durante los meses de agosto y setiembre de 2018. La encuesta se aplicó de forma directa en cada uno de los negocios correspondientes.

El total de comerciantes activos en el proyecto asciende a 18, de los cuales fue posible encuestar a 15 de ellos, representando estos un $83 \%$ de esta población.

\section{Asociados}

En el caso de los asociados, se establecieron dos condiciones para definir la población de estudio, la primera es que recibieran UDIS, es decir que como parte de su vínculo con la cooperativa hayan recibido estos vales como medio de pago alternativo, esto hasta la fecha en que fue suspendido temporalmente el programa de incentivos por compras en las unidades de negocios de esta empresa; y la segunda variable es que estos asociados fueran del cantón de Grecia.

Respecto a la variable de que hayan participado en el proyecto, esta información fue suministrada por la cooperativa, en el caso de que su lugar de domicilio sea el cantón de Grecia, y ante la ausencia de información certera sobre el domicilio de los asociados, fue necesario agruparlos por su número de teléfono, toda vez que ha sido práctica del más importante proveedor de este servicio, de que los 4 primeros números de teléfono identifican la zona o el cantón de residencia del abonado.

Al considerar lo anterior y mediante el uso de métodos probabilistas se obtuvo una muestra aleatoria de 89 asociados, trabajando con un nivel de confianza de 95\% y un margen de error del $5 \%$.

Por otra parte, y dada la dispersión de los asociados por todo el cantón de Grecia, se utilizó el teléfono como medio para realizar la encuesta, finalmente y dado que de forma natural la tasa de respuesta por este medio tiende a ser mucho más baja que las encuestas realizadas de forma personal, finalmente de la muestra mencionada, solo fue posible encuestar a 50 asociados, lo que corresponde a un $56 \%$ de la muestra inicial elegida aleatoriamente. 
De esta manera, se realizó una serie de encuestas siguiendo una guía de preguntas de investigación para cubrir los objetivos establecidos en el trabajo de investigación. Los resultados se exponen fundamentalmente anclados a los beneficios económicos y sociales, que las diferentes poblaciones reconocen por su vinculación con el uso de las UDIS, incluyendo además algunos datos generales de las personas encuestadas, tales como sexo y tiempo de participar en este proyecto. Se expone principalmente la valoración de los encuestados sobre las fortalezas y debilidades del proyecto, así como su percepción a partir de sus experiencias, sobre la posibilidad de que pueda ser desarrollado en otras cooperativas del país.

\section{Resultados}

De acuerdo con las respuestas de los 93 encuestados, se observa que no existe paridad en cuanto al género de las personas encuestadas. Los datos que se desprenden de las encuestas indican que a estas respondieron 54 hombres y 38 mujeres, solo hubo una persona que no respondió a esta pregunta, sin embargo, lo anterior demuestra que, aunque predominan los hombres, las mujeres conforman también un grupo importante de personas que alimentan al proyecto.

Además, se desprende de las encuestas a los comerciantes, que el tipo de actividad de los negocios se clasifica de la siguiente manera: 11 se dedican a la venta de bienes y 4 indicaron que venden servicios. Lo que se puede traducir en una sectorialización muy pronunciada del sector comercial hacia la venta de bienes.

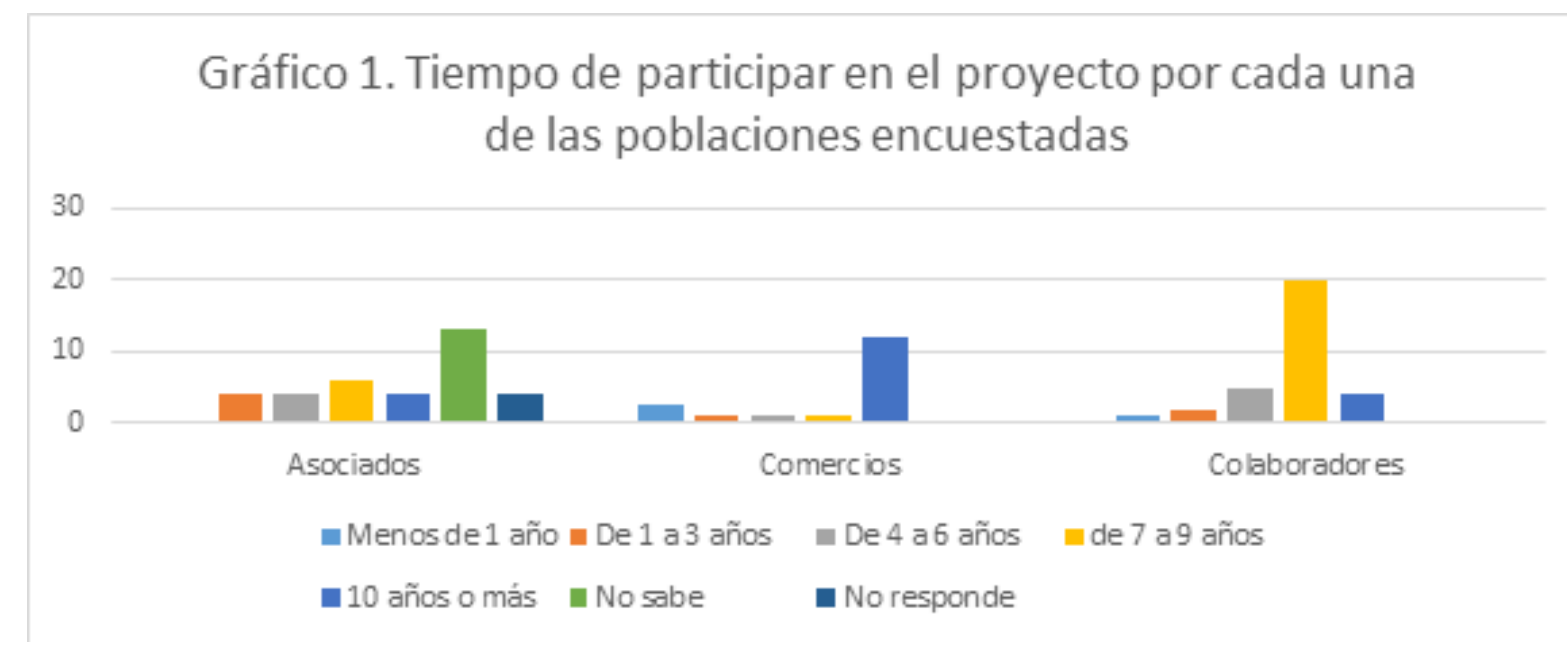

Fuente: Elaboración propia. Cuestionario aplicado (2018).

En cuanto al tiempo de participar en el proyecto de UDIS que se desarrolla en CoopeVictoria, es de resaltar que de la mayor parte de los asociados, 13 personas indicaron no saber durante cuánto tiempo fue su participación en el proyecto hasta el año 2018, y el resto de ellos indicó que participó en él en un rango de entre 1 y 9 años. Con relación a los comerciantes, 12 encuestados comentaron que participan hace más de 10 años recibiendo UDIS, los otros tres participan en un rango de entre 1 y 9 años.
Finalmente respecto a la población de colaboradores, la mayoría de ellos (2o personas), indicó que tenían de participar en el proyecto entre 7 y 9 años, 5 mencionaron que llevan participando entre 4 y 6 años y 2 indicaron que su participación tiene entre 1 y 3 años. 


\section{Cuadro 1: Evaluación del proyecto de UDIS que desarrolla CoopeVictoria}

\begin{tabular}{|c|c|c|c|c|c|c|c|c|c|c|c|c|c|c|}
\hline \multirow{3}{*}{ Población } & \multicolumn{12}{|c|}{ Cuadro \# 2 Evaluación del proyecto UDIS que desarrolla Coopevictoria,2018. } & & \\
\hline & \multicolumn{2}{|r|}{ Excelente } & \multicolumn{2}{|c|}{ Muy Bueno } & \multicolumn{2}{|r|}{ Bueno } & \multicolumn{2}{|r|}{ Regular } & \multicolumn{2}{|r|}{ Malo } & \multicolumn{2}{|c|}{ No responde } & \multicolumn{2}{|r|}{ Total } \\
\hline & $\mathbf{n}$ & Proporción & $\mathbf{n}$ & Proporción & $\mathbf{n}$ & Proporción & $\mathbf{n}$ & Proporción & n & Proporción & $\mathbf{n}$ & Proporción & n & Proporción \\
\hline Asociados & 4 & 0,08 & 12 & 0,24 & 24 & 0,48 & 5 & 0,10 & 0 & 0 & 5,00 & 0,1 & 50,00 & 0,54 \\
\hline Colaboradores & 1 & 0,04 & 9 & 0,32 & 17 & 0,61 & 1 & 0,04 & 0 & 0 & 0,00 & 0 & 28,00 & 0,30 \\
\hline Comercios & 1 & 0,07 & 1 & 0,07 & 1 & 0,07 & 5 & 0,33 & 4 & 0,27 & 3,00 & 0,2 & 15,00 & 0,16 \\
\hline Total & 6 & 0,06 & $22^{\prime}$ & 0,24 & $42^{\prime}$ & 0,45 & $11^{\prime}$ & 0,12 & 4 & 0,04 & 8 & 0,09 & 93 & 1 \\
\hline
\end{tabular}

Fuente: Elaboración propia. Cuestionario aplicado (2018).

En cuanto a la evaluación que hacen el total de los encuestados al proyecto de UDIS que se desarrolla en CoopeVictoria, se evidencia que el o,45 afirmaron que el proyecto es bueno, teniendo dentro de este caso los colaboradores la mejor del mismo con un o,61, mientras que los asociados un 0,48 y los comercios apenas un 0,07; lo que podría traducirse en términos generales en que existen mejoras que se le podrían hacer a este para llegar a la excelencia. Además, el o,24 del total de los encuestados calificó el proyecto como muy bueno y el o,06 indicó que es excelente. En términos generales se puede evidenciar que son los comerciantes los más disconformes con este proyecto, pues un 0,33 de ellos lo señala como regular, mientras que un 0,10 de los asociados tienen esta misma percepción y tan solo un 0,04 de los colaboradores piensa lo mismo; además el o,27 de los comercios piensan que el proyecto es malo, mientras que ninguno de los asociados ni los colaboradores tienen esta percepción.

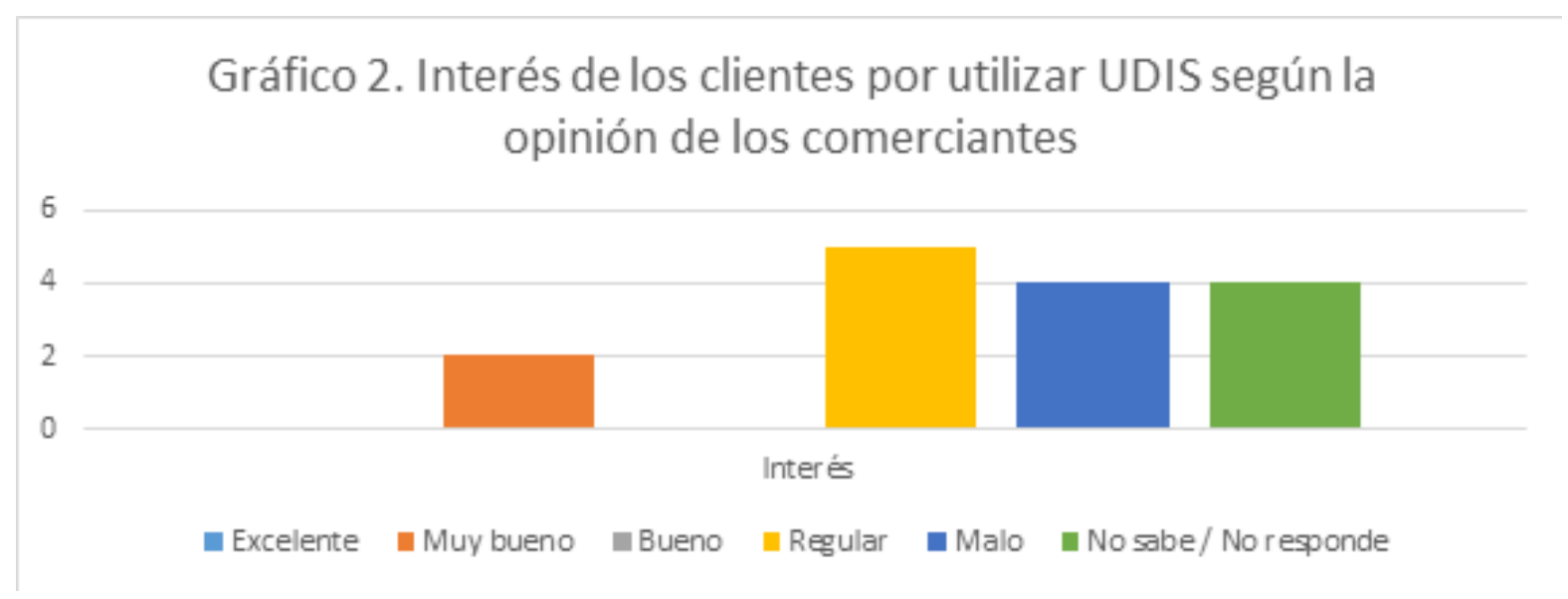

Fuente: Elaboración propia. Cuestionario aplicado (2018).

Específicamente a los comerciantes que reciben esta moneda alternativa como medio de pago, se les preguntó sobre el interés de los clientes por utilizar UDIS, a lo que respondieron de la siguiente manera: ninguno indicó que sus clientes posean un excelente interés en usar UDIS como medio de pago, el mismo resultado ocurrió con la respuesta de que exista un interés bueno; 2 indicaron que sus clientes poseen un interés muy bueno, 5 un interés regular, 4 un interés malo y 4 no saben o no responden. De lo anterior se evidencia que de acuerdo con la percepción de los comerciantes, la mayor parte de sus clientes tienen un interés apenas regular o malo por utilizar las UDIS como medio de pago. 


\section{Implicaciones sociales de las UDIS}

\section{Cuadro 2: El proyecto UDIS ha traído beneficios sociales a las poblaciones}

\begin{tabular}{lllllllll} 
Población & Sí & & No & \multicolumn{2}{c}{ No responde } & \multicolumn{2}{c}{ Total } \\
Asociados & $\mathbf{n}$ & Proporción & $\mathbf{n}$ & Proporción & $\mathbf{n}$ & Proporción & n & Proporción \\
Colaboradores & 37 & 0,74 & 7 & 0,14 & 6 & 0,12 & 50 & 0,54 \\
Comercios & 21 & 0,75 & 6 & 0,21 & 1 & 0,04 & 28 & 0,30 \\
Total & 3 & 0,20 & 10 & 0,67 & 2 & 0,13 & 15 & 0,16 \\
\hline
\end{tabular}

Fuente: Elaboración propia. Cuestionario aplicado (2018).

En cuanto a los beneficios sociales que el proyecto de UDIS que se desarrolla en CoopeVictoria les ha traído a los encuestados se obtuvo que la mayoría de los asociados, el 0,74, y de los colaboradores, el o,75, reconoce que sí les ha traído este tipo de beneficios, mientras que la mayoría de los comercios, o,67, indican que no les ha traído a ellos ningún tipo de beneficio social. Es de esta manera como se puede observar que existe una relación entre los asociados y colaboradores por inclinarse a responder de manera afirmativa, pero que contrasta claramente con la opinión de los comerciantes.

\section{Cuadro 3: El proyecto UDIS ha traído beneficios sociales a CoopeVictoria}

\begin{tabular}{|c|c|c|c|c|c|c|c|c|c|c|}
\hline \multirow{2}{*}{ Población } & \multicolumn{2}{|l|}{ Sí } & \multicolumn{2}{|c|}{ No } & \multicolumn{2}{|c|}{ No responde } & \multicolumn{2}{|c|}{ No sabe } & \multicolumn{2}{|c|}{ Total } \\
\hline & $\mathbf{n}$ & Proporción & $\mathbf{n}$ & Proporción & $\mathbf{n}$ & Proporción & $\mathbf{n}$ & Proporción & $\mathbf{n}$ & Proporción \\
\hline Asociados & 31 & 0,62 & 7 & 0,14 & 7 & 0,14 & 5 & 0,10 & 50 & 0,54 \\
\hline Colaboradores & 19 & 0,68 & 6 & 0,21 & 3 & 0,11 & o & 0,00 & 28 & 0,30 \\
\hline Comercios & 6 & 0,40 & 1 & 0,07 & 2 & 0,13 & 6 & 0,40 & 15 & 0,16 \\
\hline Total & 56 & 0,60 & 14 & 0,15 & 12 & 0,13 & 11 & 0,12 & 93 & 1 \\
\hline
\end{tabular}

Fuente: Elaboración propia. Cuestionario aplicado (2018).

Según la pregunta de si el proyecto de UDIS ha traído beneficios sociales a CoopeVictoria, el o,6o de los encuestados respondieron de manera afirmativa, el o,15 respondió negativamente, el o,12 no sabe y el o,13 no respondió. Es de esta forma que se podría consolidar la idea de que el proyecto efectivamente ha impulsado el desarrollo social de CoopeVictoria, sin embargo, es claro que nuevamente son los asociados y los colaboradores (o,62 y o68 respectivamente), quienes en mayor proporción piensan que este proyecto le ha aportado beneficios sociales a esta Cooperativa, pues en el caso de los comerciantes solo el o,40 de ellos tiene esta percepción. Lo anterior podría confirmar el postulado de que CoopeVictoria, desde sus valores y visión cooperativa, se ha dedicado a mejorar la condición socioeconómica de los colaboradores y productores agrícolas en su área de influencia. 


\section{Cuadro 4: El proyecto UDIS ha traído beneficios sociales al cantón de Grecia}

\begin{tabular}{|c|c|c|c|c|c|c|c|c|c|c|}
\hline \multirow{2}{*}{ Población } & \multicolumn{2}{|l|}{ Sí } & \multicolumn{2}{|c|}{ No } & \multicolumn{2}{|c|}{ No sabe } & \multicolumn{2}{|c|}{ No responde } & \multicolumn{2}{|c|}{ Total } \\
\hline & $\mathbf{n}$ & Proporción & $\mathbf{n}$ & Proporción & $\mathbf{n}$ & Proporción & $\mathbf{n}$ & Proporción & $\mathbf{n}$ & Proporción \\
\hline Asociados & 29 & 0,58 & 6 & 0,12 & 10 & 0,20 & 5 & 0,10 & 50 & 0,54 \\
\hline Colaboradores & 21 & 0,75 & 2 & 0,07 & 5 & 0,18 & $\mathrm{o}$ & 0,00 & 28 & 0,30 \\
\hline Comercios & 3 & 0,20 & 5 & 0,33 & 5 & 0,33 & 2 & 0,13 & 15 & 0,16 \\
\hline Total & 53 & 0,57 & 13 & 0,14 & 20 & 0,22 & 7 & 0,08 & 93 & 1,00 \\
\hline
\end{tabular}

Fuente: Elaboración propia. Cuestionario aplicado (2018).

Por otra parte, se le consultó a los encuestados si el proyecto de UDIS ha traído beneficios sociales al cantón de Grecia. El o,57 de las personas indicó que el proyecto sí ha traído beneficios a la parte social del cantón, sin embargo, nuevamente son los comerciantes quienes son mucho más escépticos sobre los aportes de este proyecto, pues en este caso solo el o,20 del total de comercios señaló que sí existen beneficios sociales para el cantón de Grecia, contra un 0,58 de los asociados y un 0,75 de los colaboradores que piensa lo mismo. Por otra parte el o,14 del total de las personas encuestadas indicó que no trae beneficios sociales al cantón de Grecia, siendo los comerciantes (con un 0,33) los que mayoritariamente tienen esta percepción. Finalmente el o,30 del total de los encuestados indicó no saber o no respondieron.

\section{Cuadro 5: Listado de beneficios sociales del proyecto UDIS según las poblaciones encuestadas}

\begin{tabular}{|c|c|c|c|c|}
\hline Listado de beneficios del proyecto & Asociados & Comercio & Colaboradores & Total \\
\hline Se ha favorecido el cuidado del medio ambiente & 10 & 4 & 14 & 28 \\
\hline Ha favorecido la cooperación y confianza entre las personas & 21 & 3 & 17 & 41 \\
\hline Han disminuido los robos o hurtos por parte de los antisociales & 21 & 6 & 8 & 35 \\
\hline Ha favorecido la participación social y el espíritu comunitario & 8 & 2 & 17 & 27 \\
\hline Ha permitido el crecimiento de CoopeVictoria & 11 & n.a. & 15 & 26 \\
\hline
\end{tabular}

Fuente: Elaboración propia. Cuestionario aplicado (2018).

De acuerdo con la percepción de las poblaciones encuestadas, y según se evidencia en el cuadro anterior, a modo de resumen se entiende que el principal beneficio social generado, es que el proyecto UDIS ha impulsado la cooperación y confianza entre las personas, (41 encuestados en total tienen esta percepción), sin embargo pese a que es la opción más citada por ellos, en ninguna de las tres poblaciones existe una mayoría que esté de acuerdo con esta posición, por otra parte se cita también como un beneficio, que han disminuido los robos o hurtos por parte de los antisociales, con esta posición coinciden 35 de los 93 encuestados, que es equivalente al o,37 de todas las personas a quienes se les aplicó la encuesta.
También 28 encuestados coinciden en que se ha favorecido el cuidado del medio ambiente, 27 que ha favorecido la participación social y el espíritu comunitario, y 26 de ellos, indican que este proyecto ha permitido el crecimiento de CoopeVictoria.

Puntualmente en el caso del cuidado del medio ambiente, si bien es cierto la mayor parte de los encuestados no ven en el proyecto, un medio para favorecer este cuidado, es importante señalar que de acuerdo con las encuestas realizadas, y por la dinámica que conlleva la producción de biodiesel, es evidente que dicha iniciativa desarrollada por CoopeVictoria es sin lugar a dudas sumamente valiosa, y constituye un ejemplo a emular por otras empresas, principalmente si forman parte de la economía social solidaria. 
En el caso de las celdas que el cuadro anterior se marcan como "n.a.", obedece es porque la pregunta efectuada no se incluyó en el cuestionario que se les aplicó a los comercios, debido a que esta población no tiene un vínculo tan directo con la cooperativa como sí lo tienen los asociados y los colaboradores.

\section{Implicaciones económicas de las UDIS}

\begin{tabular}{|c|c|c|c|c|c|c|c|c|}
\hline \multicolumn{9}{|c|}{ Cuadro 6: El proyecto UDIS ha traído beneficios económicos a las poblaciones } \\
\hline \multirow{2}{*}{ Población } & \multicolumn{2}{|l|}{ Sí } & \multicolumn{2}{|c|}{ No } & \multicolumn{2}{|c|}{ No responde } & \multicolumn{2}{|c|}{ Total } \\
\hline & $\mathrm{n}$ & Proporción & $\mathbf{n}$ & Proporción & n & Proporción & $\mathrm{n}$ & Proporción \\
\hline Asociados & 39 & 0,78 & 5 & 0,29 & 6 & 0,75 & 50 & 0,54 \\
\hline Colaboradores & 22 & 0,79 & 6 & 0,35 & o & 0,00 & 28 & 0,30 \\
\hline Comercios & 4 & 0,27 & 9 & 0,53 & 2 & 0,25 & 15 & 0,16 \\
\hline Total & 65 & 0,70 & 20 & 0,22 & 8 & 0,09 & 93 & 1,00 \\
\hline
\end{tabular}

Fuente: Elaboración propia. Cuestionario aplicado (2018).

Se les consultó a los encuestados si el proyecto de UDIS que se desarrolla en CoopeVictoria les ha traído beneficios económicos a ellos mismos. Como respuesta a esta consulta, el o,78 de los asociados y el o,79 de los colaboradores indicaron que el proyecto sí les aporta o aportó beneficios económicos, caso contrario en los comercios, donde la mayoría de los encuestados (el o,53), más bien indicó que el proyecto no les ha traído este tipo de beneficios. Tal como es evidente, una buena parte de los asociados y colaboradores señalan que en términos económicos les ha sido beneficiosa esta iniciativa, según la cual a los asociados se les cancelaba en UDIS los premios por sus compras en los negocios de la Cooperativa, y a los colaboradores se les cancela parte de su salario como ya se ha descrito en apartados anteriores.

\section{Cuadro 7: El proyecto UDIS ha traído beneficios económicos a CoopeVictoria}

\begin{tabular}{|c|c|c|c|c|c|c|c|c|c|c|}
\hline \multirow{2}{*}{ Población } & \multicolumn{2}{|l|}{ Sí } & \multicolumn{2}{|c|}{ No } & \multicolumn{2}{|c|}{ No responde } & \multicolumn{2}{|c|}{ No sabe } & \multicolumn{2}{|c|}{ Total } \\
\hline & $\mathbf{n}$ & Proporción & $\mathbf{n}$ & Proporción & $\mathbf{n}$ & Proporción & $\mathbf{n}$ & Proporción & $\mathbf{n}$ & Proporción \\
\hline Asociados & 32 & 0,64 & 5 & 0,10 & 5 & 0,10 & 8 & 0,16 & 50 & 0,54 \\
\hline Colaboradores & 21 & 0,75 & 4 & 0,14 & $\mathrm{O}$ & 0,00 & 3 & 0,11 & 28 & 0,30 \\
\hline Comercios & 4 & 0,27 & 1 & 0,07 & 8 & 0,53 & 2 & 0,13 & 15 & 0,16 \\
\hline Total & 57 & 0,61 & 10 & 0,11 & 13 & 0,14 & 13 & 0,14 & 93 & 1 \\
\hline
\end{tabular}

Fuente: Elaboración propia. Cuestionario aplicado (2018).

De acuerdo con la pregunta realizada a los encuestados, en el sentido de que si desde su perspectiva el proyecto UDIS ha traído beneficios económicos a CoopeVictoria, el o,64 de los asociados, y el 0,75 de los colaboradores indicaron que sí trae estos beneficios a la cooperativa, mientras que en el caso de los comerciantes, mucho más escépticos respecto a las bondades del proyecto, solamente el o,27 de ellos piensan lo mismo, mientras que el o,66 de ellos más bien señala que no sabe o no responde. 


\section{Cuadro 8: El proyecto UDIS ha traído beneficios económicos al cantón de Grecia}

\begin{tabular}{|c|c|c|c|c|c|c|c|c|c|c|}
\hline \multirow{2}{*}{ Población } & \multicolumn{2}{|l|}{ Sí } & \multicolumn{2}{|c|}{ No } & \multicolumn{2}{|c|}{ No sabe } & \multicolumn{2}{|c|}{ No responde } & \multicolumn{2}{|c|}{ Total } \\
\hline & $\mathrm{n}$ & Proporción & $\mathrm{n}$ & Proporción & $\mathrm{n}$ & Proporción & $\mathrm{n}$ & Proporción & $\mathrm{n}$ & Proporción \\
\hline Asociados & 36 & 0,72 & 5 & 0,10 & 4 & 0,08 & 5 & 0,10 & 50 & 0,54 \\
\hline Colaboradores & 18 & 0,64 & 3 & 0,11 & 7 & 0,25 & $\mathrm{o}$ & 0,00 & 28 & 0,30 \\
\hline Comercios & 3 & 0,20 & 5 & 0,33 & 5 & 0,33 & 2 & 0,13 & 15 & 0,16 \\
\hline Total & 57 & 0,61 & 13 & 0,14 & 16 & 0,17 & 7 & 0,08 & 93 & 1 \\
\hline
\end{tabular}

Fuente: Elaboración propia. Cuestionario aplicado (2018).

También se les consultó a los encuestados si el proyecto de UDIS ha traído beneficios económicos al cantón de Grecia. El o,61 de las personas indicaron que el proyecto sí trae beneficios a la economía del cantón, el o,14 de las personas indicaron que no trae beneficios y el 0,25 de las personas indicaron no saber o no respondieron. Sin embargo, es importante destacar que nuevamente los comerciantes no muestran el mismo nivel de satisfacción que las otras poblaciones.

Por otra parte, se les consultó a los dueños de los comercios si ofrecen algún porcentaje de descuento a los clientes que pagan o cancelan sus compras con UDIS. De estos encuestados, 9 respondieron afirmativamente, 4 respondieron que no ofrecen descuentos y 2 personas no respondieron.
Se les consultó además a los comerciantes cuál es el porcentaje de descuento que les ofrecen a los clientes al paga con UDIS en sus negocios, a lo que 8 encuestados respondieron que manejan un rango de descuentos de entre o y $4 \%$, y 6 indicaron que los descuentos son de entre un 5 y un $10 \%$. Con lo anterior se evidencia que la mayor parte de los negocios sí utiliza algún tipo de descuento para quienes cancelen en UDIS, lo que en definitiva resulta un atractivo para los clientes que forman parte de la red de participantes en el proyecto.

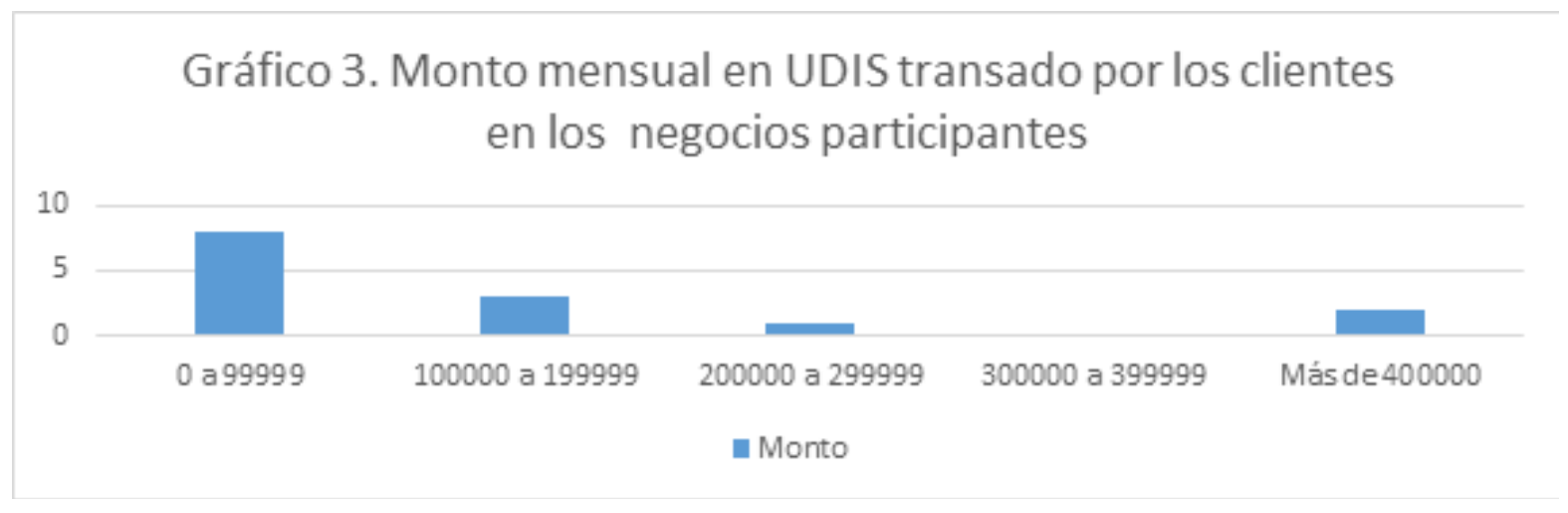

Fuente: Elaboración propia. Cuestionario aplicado (2018). 
En cuanto al monto mensual transado en UDIS en los comercios, se obtuvo que 8 comercios transan entre o y 99.999 UDIS al mes, mientras que 3 transan entre 100.000 y 199.999, 1 comercio transa entre 200.000 y 299.999 UDIS al mes, y 2 comercios transan más de 400.00o UDIS al mes, lo que evidentemente se interpreta que las transacciones en UDIS son realmente ínfimas, esto principalmente dado el tamaño de la población total de Grecia, aproximadamente 16000 habitantes, y la población económica activa en este cantón.

Cuadro 9: Listado de beneficios económicos del proyecto UDIS según las poblaciones encuestadas

\begin{tabular}{|l|l|l|l|l|}
\hline Listado de beneficios del proyecto & Asociados & Comercio & Colaboradores \\
\hline Ha mejorado sus ingresos. & 39 & 3 & 3 & Total \\
\hline Ha mejorado su capacidad de ahorro & 36 & 0 & 26 & 45 \\
\hline Ha mejorado los ingresos de la cooperativa & 30 & n.a. & 12 & 42 \\
\hline $\begin{array}{l}\text { Usted obtiene mejores descuentos en los comercios locales afiliados } \\
\text { al programa }\end{array}$ & 24 & 4 & 42 \\
\hline $\begin{array}{l}\text { Permite que el dinero que se genere en el cantón se invierta en el } \\
\text { mismo cantón }\end{array}$ & 24 & 7 & 40 \\
\hline Ha favorecido el ahorro por parte de los participantes en el proyecto & 22 & 21 & 15 & 55 \\
\hline Ha mejorado los ingresos de los comercios afiliados & 21 & 3 & 14 \\
\hline El uso de las UDIS ha fortalecido la economía del cantón & 2 & 24 \\
\hline $\begin{array}{l}\text { Ha sido una buena experiencia para lograr que el Banco Central } \\
\text { tolere uso de monedas alternativas }\end{array}$ & 9 & 2 & 38 \\
\hline
\end{tabular}

Fuente: Elaboración propia. Cuestionario aplicado (2018).

De la información anterior y tomando como referencia las encuestas aplicadas a las poblaciones, se obtiene que los beneficios económicos que promueve el uso de UDIS en CoopeVictoria son varios, destacándose fundamentalmente en el caso de los asociados y colaboradores, que debido al proyecto ha mejorado su capacidad de ahorro (62 personas en total de estas poblaciones coinciden en este sentido), condición eso si con la cual no están de acuerdo ninguno de los comerciantes encuestados, y destaca en este sentido la opinión de los colaboradores donde 26 de los 28 encuestados estuvieron de acuerdo en señalar que este es un beneficio del uso de las UDIS, y se considera totalmente comprensible estos resultados, pues como ya ha sido mencionado, los colaboradores voluntariamente eligen que un porcentaje de su salario sea cancelado en UDIS, lo cual incentiva el ahorro, sobre todo al considerar que estos vales solo pueden usarse en una cantidad limitada de negocios.
También respecto al tema del ahorro, una cantidad menor de personas coinciden en que el proyecto ha favorecido en términos generales esta conducta, entre todos los participantes del proyecto, evidenciándose en el caso de los colaboradores, que solo 15 de ellos opinan favorablemente en este sentido, mientras que como ya se citó anteriormente, de forma individual mayoritariamente ellos señalaron que sí mejoró su capacidad de ahorro.

Por su parte, una de las bondades adicionales que en términos económicos se achaca al uso de las monedas alternativas en general es precisamente el hecho de que se fortalece la economía de las comunidades, en este sentido como puede observarse, 55 de las 93 personas encuestadas señalan que las UDIS permiten que el dinero que se genera en el cantón se invierta en el mismo cantón; y como complemento a esto, 48 personas indican que el uso de estos vales ha fortalecido la economía del cantón. 
Con respecto al tema de la mejoría en los ingresos personales por usar UDIS, esta opinión es ampliamente apoyada por los asociados a la cooperativa, pues $39 \mathrm{de}$ los 50 encuestados así lo señalan, y esto es entendible y coincidente con lo planteado por CoopeVictoria, en el sentido de que a los asociados hasta este año se les apoyaba con un 2\% de bonificación en UDIS, por las compras realizadas en los negocios de la misma cooperativa.

Como puede observarse, se citan otros beneficios por parte de las poblaciones como el hecho de que han mejorado los ingresos de los comercios o de la cooperativa por ejemplo, y en menor medida solo 24 de los 93 encuestados señalan, que el uso de UDIS ha sido una buena experiencia para lograr que el Banco Central tolere uso de monedas alternativas.

\section{Fortalezas y debilidades}

Con relación a las fortalezas del proyecto, estas han sido abordadas básicamente desde la percepción de las poblaciones sobre los beneficios económicos y sociales que el proyecto ofrece; en cuanto a las debilidades detectadas, estas se detallan seguidamente.

Cuadro 10: Debilidades del proyecto UDIS

\begin{tabular}{|c|c|c|c|c|c|c|c|c|c|c|}
\hline \multirow{2}{*}{ Población } & \multicolumn{2}{|l|}{ Sí } & \multicolumn{2}{|l|}{ No } & \multicolumn{2}{|c|}{ No sabe } & \multicolumn{2}{|c|}{ No responde } & \multicolumn{2}{|c|}{ Total } \\
\hline & $\mathbf{n}$ & Proporción & $\mathbf{n}$ & Proporción & $\mathbf{n}$ & Proporción & $\mathbf{n}$ & Proporción & $\mathbf{n}$ & Proporción \\
\hline Asociados & 15 & 0,30 & 10 & 0,20 & 18 & 0,36 & 7 & 0,14 & 50 & 0,54 \\
\hline Colaboradores & 15 & 0,54 & 3 & 0,11 & 8 & 0,29 & 2 & 0,07 & 28 & 0,30 \\
\hline Comercios & 8 & 0,53 & 4 & 0,27 & $\mathrm{o}$ & 0,00 & 3 & 0,20 & 15 & 0,16 \\
\hline Total & 38 & 0,41 & 17 & 0,18 & 26 & 0,28 & 12 & 0,13 & 93 & $1, \mathrm{OO}$ \\
\hline
\end{tabular}

Fuente: Elaboración propia. Cuestionario aplicado (2018).

De acuerdo con la pregunta de si considera que el proyecto UDIS desarrollado por CoopeVictoria tiene debilidades, el o,41 de las personas indicó que sí las posee, el o,18 de las personas argumentan que no posee debilidades, mientras que el o,28 de las personas indicaron no saber, y el o,13 no respondieron. Se presenta enseguida las debilidades que mayoritariamente las diferentes poblaciones indicaron que presenta esta iniciativa.

Entre las personas que indicaron que el proyecto sí tiene debilidades, 29 de ellas señalaron como la principal debilidad que ha hecho falta que CoopeVictoria promocione más el proyecto, 24 encuestados señalaron que son pocos los negocios que reciben las UDIS como medio de pago, 23 personas sugieren que la población en general desconoce la existencia de este proyecto, 17 que el proyecto no es abierto para la participación de toda la comunidad y 7 que ha generado tensiones con el Banco
Central, además 6 personas señalaron como debilidad el hecho de que no ha existido constancia en el desarrollo mismo. Entre otras debilidades los encuestados señalaron además que debería haber reuniones más seguidas, existir más información de proyectos y comercios afiliados, así como mayor publicidad.

Por otra parte, además, se les consultó a los encuestados si el proyecto UDIS podría desarrollarse en otras cooperativas del país, de las personas que decidieron responder (67), 63 de ellas que equivalen a un 0.9 respondieron de manera afirmativa, y 4 de ellas que equivalen a un 0.10 indicaron que no podría desarrollarse en otras cooperativas. De esta manera queda claro que las tres poblaciones que tienen o han tenido una interacción directa con el proyecto y que por tanto lo conocen a fondo, tienen la percepción de que pese a sus debilidades es perfectamente extrapolable a otras cooperativas del país. 
Finalmente, se abrió un espacio para que los encuestados aportarán recomendaciones para mejorar el proyecto, entre las cuales destacan: que se siga adelante con el proyecto, que haya más publicidad y más información para atraer a más personas para crear más confianza y fortalecer el proyecto, que se retome con más fuerza el proyecto de UDIS, que haya más comercios afiliados, que el proyecto se extienda a nivel nacional, que utilicen solo en productos, que exista mejor financiamiento, que se pueda aumentar la cuota para poder ahorrar UDIS en suministros y gasolineras, y que sea un mecanismo de uso exclusivo para los productores.

\section{Conclusiones}

Con el transcurso de los años han emergido nuevos modelos y prácticas que proponen nuevas lógicas de pensamiento, y que en alguna medida tienen la condición de irreverentes a los sistemas hegemónicos; de esta forma y como parte de la economía social solidaria, el cooperativismo propone un modelo de desarrollo cuyo fundamento se antepone al fin de lucro como objetivo final, y más bien su modelo se centra en el cumplimiento de principios que procuran el bien común de sus asociados.

En esta misma dinámica, el concepto de monedas complementarias, particularmente en los últimos años, ha venido teniendo un fuerte desarrollo en varias latitudes, buscando sin sustituir a las monedas de curso ordinario, normalmente favorecen el desarrollo social y económico de los participantes en estos proyectos, que a su vez tienen la condición de comunitarios.

CoopeVictoria, como la cooperativa más antigua de Costa Rica, como parte de sus acciones en busca del bienestar de sus asociados y de la comunidad, en el año 2007 desarrolla el proyecto de moneda complementaria llamado UDIS como un mecanismo para fortalecer el intercambio de bienes y servicios entre los participantes, para fortalecer así la economía comunitaria, procurando además acciones en pro del medio ambiente como la producción de biodiesel.
Con relación a la valoración global del proyecto UDIS por parte de las personas encuestadas, se evidenció que de forma mayoritaria hay coincidencia en el sentido de que el proyecto es bueno o muy bueno, alcanzando una proporción de un o,69 de estas personas que se inclinan por estas valoraciones, siendo los comerciantes las personas con opiniones mayormente desfavorables, alcanzando un 0,33 de ellos que piensan que el proyecto es apenas regular y un 0,27 que piensan que es malo.

De acuerdo con la percepción de los comerciantes que respondieron, sobre el interés de los clientes por utilizar UDIS como medio de pago, se denota que este interés es apenas regular o malo, alcanzando este criterio el o,82 del total de los comerciantes que atendieron esta consulta.

Con relación a los beneficios sociales puntuales, en orden de importancia las poblaciones reconocen que el proyecto ha favorecido la cooperación y confianza entre las personas, ha permitido una disminución de los robos o hurtos por parte de los antisociales, se ha favorecido el cuidado del medio ambiente, ha favorecido la participación social y el espíritu comunitario, y finalmente que ha permitido el crecimiento de CoopeVictoria.

Puntualmente en el caso del cuidado del medio ambiente, si bien es cierto la mayor parte de los encuestados no ven en el proyecto un medio para favorecer este cuidado, es importante señalar que de acuerdo con las encuestas realizadas, y por la dinámica que conlleva la producción de biodiesel, es evidente que dicha iniciativa desarrollada por CoopeVictoria es sin lugar a dudas sumamente valiosa, y constituye un ejemplo a emular por otras empresas, principalmente si forman parte de la economía social solidaria.

Aparte del factor ambiental, otro beneficio importante que se concluye del proyecto de Biodiesel, es el hecho de que mejora los ingresos de las escuelas, genera empleos adicionales para el transporte y fabricación del producto, además de que fomenta la disciplina en los niños de edad escolar. 
De acuerdo con las consultas realizadas a los comerciantes se logra determinar que la mayor parte de los negocios utiliza algún tipo de descuento para quienes cancelen en UDIS, lo que en definitiva resulta un atractivo para los clientes que forman parte de la red de participantes en el proyecto.

En relación con los beneficios económicos que señalan las poblaciones encuestadas, en orden de importancia las personas reconocen que el proyecto ha mejorado su capacidad de ahorro, permiten que el dinero que se genera en el cantón se invierta en el mismo cantón, ha fortalecido la economía del cantón, ha favorecido el ahorro en términos generales de todos los participantes del proyecto, se obtienen mejores descuentos en los comercios afiliados al proyecto, ha mejorado los ingresos de los comercios afiliados y de la cooperativa, y finalmente ha sido una buena experiencia para lograr que el banco central tolere el uso de monedas alternativas.

A partir de las consultas hechas a las poblaciones, se concluye en orden de importancia las debilidades que presenta el proyecto: ha hecho falta que CoopeVictoria promocione más el proyecto, son pocos los negocios que reciben las UDIS como medio de pago, la población en general desconoce la existencia de este proyecto, este no es abierto para la participación de toda la comunidad, ha generado tensiones con el Banco Central, y finalmente que no ha existido constancia en el desarrollo mismo.

En relación con la valoración de las poblaciones que tienen conocimiento directo por participar en esta iniciativa de UDIS, el o.9 de ellas valoran como posible que dicha iniciativa pueda desarrollarse en otras cooperativas del país. Es valioso rescatar esta percepción, pues pese a las debilidades del proyecto, se cree que efectivamente e tiene la factibilidad de poder desarrollarse en otras cooperativas del país, lo que demuestra que en buena medida existe ímpetu por la iniciativa, además de que se confía en la capacidad del movimiento cooperativo para su desarrollo.
A modo de resumen, existe en términos generales una percepción positiva de los beneficios sociales y económicos de este proyecto por parte de los asociados y colaboradores, pero de parte de los comerciantes su valoración general sobre las bondades del proyecto es bastante escasa o limitada, pero esto no ha sido un detonante para que los comerciantes abandonen en forma definitiva su participación, puesto que este inició con 19 participantes y se mantiene a la fecha del estudio con una participación de 18, aunque con el transcurrir del tiempo ha existido una variación.

Si bien la percepción de los colaboradores es como ya se ha mencionado positiva, dicha valoración contrasta con la cantidad de estos que aún se mantienen recibiendo una parte de su salario en UDIS, esto por cuanto de los 50 participantes que iniciaron, a la fecha solo se mantienen 29 colaboradores formando parte de esta iniciativa.

El hecho de que la cooperativa tome la decisión de cancelar en UDIS a los colaboradores que son a su vez asociados a la cooperativa, parte de los premios recibidos por la certificación de "Comercio Justo", deja claramente evidenciado el profundo arraigo social de CoopeVictoria, pues no solo está motivando a sus empleados a convertirse en codueños del negocio, sino que además intenta dinamizar la economía del cantón mediante la inyección de UDIS.

La decisión de CoopeVictoria de ejecutar su plan de donaciones a diversas instituciones en UDIS, también refleja que esta cooperativa está comprometida con la vivencia de los valores cooperativos, y que además también es solidaria con los negocios que forman parte de la iniciativa UDIS.

En cuanto al monto mensual transado en UDIS en los comercios, y que ronda en promedio apenas los 200.000 UDIS, y considerando además que la población de Grecia asciende a 76.898 habitantes (INEC, 2011), que la población económicamente activa es de 38.004 personas (CINDE, 2018), y que la cantidad de negocios registrados en el cantón es de 2.466 (INA, 2018), dejan clara evidencia de que la circulación de UDIS mensual podría considerarse como ínfima, y que por tanto con una circulación tan 
reducida, los aportes generales del proyecto a la fecha son muy limitados, contrastando esto eso sí esta conclusión, principalmente con la percepción de algunos asociados y colaboradores sobre los resultados de esta iniciativa.

Los roces de opinión que ha tenido la Cooperativa con el Banco Central, más el hecho de la disminución en la cantidad de incentivos ofrecidos por CoopeVictoria para apoyar el proyecto (dentro de los cuales está la eliminación del pago del estímulo del $2 \%$ en UDIS, por las compras realizadas en los negocios de CoopeVictoria), han generado que la iniciativa haya venido a menos en los últimos años, presentando el proyecto una especie de impase, y análisis de los objetivos iniciales propuestos del proyecto.

\section{Bibliografía}

Alianza Cooperativa Internacional. (1995). II Asamblea General. Consultado desde https://www. aciamericas.coop/IMG/pdf/idc_1995_es-2.pdf

Ángela Zamora Chaves. Comunicación personal. 29 de Junio de 2017.

Arroyo, M. (2007). Los sistemas monetarios alternativos, un estímulo para las economías locales pobres. Consultado desde https://www.elmundo.es/ elmundo/2007/10/05/solidaridad/1191608754. html

Asamblea Legislativa. (1998) Ley 7818 - Ley orgánica de la agricultura e industria de la caña de azúcar. Consultado desde https://www.laica.co.cr/media/ docs/leyes/7818.pdf

Bogantes, A. (2010). Entre cantones. Revista mensual Febrero. Consultado desde http://www. entrecantones.net/

Bogantes, A. (2010). Proyecto de Biocombustible crece para todos. Revista Entre cantones.

Bondone, C. (2009). Capitalismo y moneda. Osmar Buyatti: Librería Editorial
Brenes, E. (2010). Monedas complementarias para economías locales sostenibles en Centro América. Tomado de http://www.agriculturesnetwork. org/magazines/latin-america/serviciosfinancieros-agricultura-campesina/monedascomplementarias-para-economias-locales consultado el 13 de abril de 2015

Brenes, E. (2013). Monedas complementarias y ambiente. Cuaderno interdisciplinar de Desarrollo Sostenible: Universidad de Calabria.

Bustamante, R.; Escoto, K.; García, E. y Turcios, E. (2012) Evaluación de la moneda alternativa como un medio que posibilita la economía solidaria; caso Estudio Suchitoto. Trabajo de graduación facultad de ciencias económicas y empresariales Universidad Centroamericana "José Simeón Cañas” Licenciatura en Economía.

Chaparro, E. (2014). Monedas comunitarias en contextos solidario. Una aproximación al sentido del uso del itacate. Tlaquepaque: ITESO.

Cinde. (2018). Presentación para la guía de inversión de la Región de Occidente. Tacares:UCR.

Cooperativas de las Américas. (s.f.) Principios y Valores Cooperativos. Consultado desde https:// www.aciamericas.coop/Principios-y-ValoresCooperativos- 4456

CoopeVictoria. (2010). U.D.I.S. (Unidades de Intercambio Solidario). Tomado de http://www.coopevictoria. com/proyectos_udis.html. Consultado el 13 de abril de 2015 .

Corrons, A. (2017). Monedas complementarias: dinero con valores. Revista Internacional de Organizaciones, $\mathrm{N}^{\circ}$ 18. Universitat Oberta de Catalunya.

Cortés, F. (s.a.) Las monedas sociales. Madrid: Cajamar 
Cristiá, F. (2016). Hacia una nueva escuela cooperativista: Cooperativismo en prospectiva. San José: Confederación de Cooperativas del Caribe y Centra América.

Cristiá, F. (2017). Entornos, tendencias, procesos de cambio y retos a las cooperativas. San José: Confederación de Cooperativas del Caribe y Centra América.

Érick Brenes Mata. Comunicación personal. 27 de junio de 2017.

Esquivel, J. (2008). CoopeVictoria incursiona en producción de Bio Diesel. Programa radial. Radio 16. 31 de julio de 2008.

Fairtrade. (s.a.) ¿Qué es Fairtrade? Consultado desde https:/sellocomerciojusto.org/es/empresas/ queesfairtrade.html

García, S. (2011). Algunos aspectos fundamentales sobre la Unidad de Intercambio Solidario-UDIS. Quito: Programa de Proyectos para el Desarrollo.

García, D. (2013) Dinero Social: UDIS en Centroamérica. Secretaría Ejecutiva del Consejo Monetario Centroamericano.

González, I. (s.a.) Aceites usados de cocina. Problemática ambiental, incidencias en redes de saneamiento y coste del tratamiento en depuradoras. Consultado desde http://residusmunicipals.cat/uploads/ activitats/docs/20170427092548.pdf

Guerra, P. (2012). Las legislaciones sobre economía social y solidaria en América Latina: Entre la autogestión y la visión sectorial. Revista de la Facultad de Derecho, $\mathrm{N}^{\circ}$ 33. Montevideo: Universidad de la República.

Henry Vargas Arrieta. Comunicación personal. 30 de noviembre de 2018.
Hirota, Y. (2011). Monedas complementarias como herramienta para fortalecer la economía social. Valencia: Universitat de Valencia.

Infocoop. (s.a.). Censo Nacional de cooperativas. Consultado desde www.infocoop.go.cr/ cooperativismo/ estadistica/censo_cooperativo_2012.pdf

INA. (2018). Estudios de detección de necesidades. Naranjo: Unidad Regional Central Occidental

INEC. (2011). Censo poblacional Costa Rica 2011. Consultado desde www.inec.go.cr/sites/default/ files/documentos/inec_institucional/estadisticas/ resultados/repoblaccenso2011-10.pdf.pdf

Lahera, I. (2013) Un enfoque teórico acerca de los valores en la contemporaneidad. Consultado desde: http://www.eumed.net/libros-gratis/2013/1277/ index.htm

La Nación. (22 de junio de 2014). Un pueblo escondido en Quepos comercia con moneda propia: el udis. Tomado de http://www.nacion.com/ nacional/escondido-Quepos-comercia-monedapropia_o_1422257817.html consultado el 13 de abril de 2015 .

La Nación, (30 de octubre de 2014). Pobreza en Costa Rica llega al nivel más alto en cinco años. Tomado de http://www.nacion.com/economia/ politica-economica/hogares-Costa-Ricapobres_o_1448255302.html Consultado el 13 de abril de 2015 .

Lietaer, B. (2008). Opciones para gestionar a crisis sistémica de la Banca. Hyderabad: Academia mundial de Artes y Ciencias.

López y Gentile. (s.a.). Sistema de indicadores económicos y sociales: la importancia del análisis integrado. Centro de investigación, seguimiento y monitoreo del desarrollo. Facultad de Ciencias Económicas y Sociales - Universidad Nacional de Mar del Plata. 
OXFAM. (2016). Una economía al servicio del 1\%. Reino Unido: Oxfam Internacional
Zamora, M.; Rodríguez, W et al. (2017). Balance Social Cooperativo 2016-2017. Grecia: CoopeVictoria

Pérez, J. (s.a.). Informe Inicial. CoopeVictoria: Inédito

Red Xuchit Tutut. (s.a.) Construyamos juntos nuestra economía solidaria: Forma parte de la red de negocios locales. El Salvador: Red Xuchit Tutut.

Rodríguez, C. (s.a.) Forjadores y pioneros de CoopeVictoria. 26 entrevistas sobre la historia de la primera cooperativa de Costa Rica. San José: Maya\&PZ

Sampieri et al. (2010). Metodología de la investigación. Madrid: McGraw Hill

Shephard, D. (2011). Las monedas complementarias y la nueva realidad de las finanzas solidarias en países desarrollados y no desarrollados. Revista Venezolana de Economía Social. Vol. 11. Mérida: Universidad de los Andes.

STRO (s.a.) Sistema de vales UDIS en CoopeSilencio. Tomado de www.stro-ca.org/es/proyectos/ sistema-de-vales-udis-en-coopesilencio Consultado el 13 de abril de 2015

STRO (s.a.) STRO en breve Tomado de http://www.stroca.org/es/historia consultado el 13 de abril de 2015

STRO (s.a.) ¿Quiénes somos? Tomado de http://www. stro-ca.org/es/quienes-somos consultado el 13 de abril de 2015

Universia, México (2010). Biodiesel, una alternativa contra la contaminación, consultado desde http:// noticias.universia.net.mx/vida-universitaria/ noticia/2010/02/23/173082/biodiesel-alternativacontra-contaminacion.pdf

Zamora, Á. (2010). Entre cantones. Revista mensual Febrero. Consultado desde http://www. entrecantones.net/ 